\title{
How Elite Partisan Polarization Affects Public Opinion Formation
}

\author{
JAMES N. DRUCKMAN Northwestern University \\ ERIK PETERSON Stanford University \\ RUNE SLOTHUUS Aarhus University
}

\begin{abstract}
Tompetition is a defining element of democracy. One of the most noteworthy events over the last quarter-century in U.S. politics is the change in the nature of elite party competition: The parties have become increasingly polarized. Scholars and pundits actively debate how these elite patterns influence polarization among the public (e.g., have citizens also become more ideologically polarized?). Yet, few have addressed what we see as perhaps more fundamental questions: Has elite polarization altered the way citizens arrive at their policy opinions in the first place and, if so, in what ways? We address these questions with a theory and two survey experiments (on the issues of drilling and immigration). We find stark evidence that polarized environments fundamentally change how citizens make decisions. Specifically, polarization intensifies the impact of party endorsements on opinions, decreases the impact of substantive information and, perhaps ironically, stimulates greater confidence in those-less substantively grounded-opinions. We discuss the implications for public opinion formation and the nature of democratic competition.
\end{abstract}

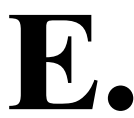

E. Schattschneider $(1960,138)$ concluded his classic book, The Semisovereign People, by defining democracy as "a competitive political system in which competing leaders and organizations define the alternatives of public policy in such a way that the public can participate in the decision-making process" (italics in original). Although his work vastly influenced the trajectory of multiple areas of political science, his concluding conception of democracy has received relatively scant attention. In this article, we take up an aspect of his definition by addressing this question: How does the tenor of political competitiona defining element of democracy-affect the nature of citizen decision making?

We focus on one of the most discussed contemporary developments in U.S. politics: elite polarization. Over the last quarter-century, elected representatives and activists from the major parties have become more ideologically distinct from one another and more internally homogeneous (e.g., McCarty, Poole, and Rosenthal 2006). Therefore, following previous work, we define elite polarization as high levels of ideological distance between parties and high levels of homogeneity within parties. Lively debate revolves around the causes and consequences of elite polarization, with notable attention to whether citizens have also become polarized. Although there is far from a consensus on the status of citizen polarization (e.g., Fiorina and Abrams 2008,

James N. Druckman is Payson S. Wild Professor, Department of Political Science, Northwestern University, Scott Hall, 601 University Place, Evanston, IL 60208 (druckman@northwestern.edu).

Erik Peterson is a graduate student, Department of Political Science, Stanford University, Encina Hall West, 616 Serra Street, Stanford, CA 94305 (erik.peterson@stanford.edu).

Rune Slothuus is Associate Professor, Department of Political Science, Aarhus University, Bartholins Alle 7, 8000 Aarhus C, Denmark (slothuus@ps.au.dk).

We thank Laurel Harbridge, Gabe Lenz, Matt Levendusky, Kerry O'Brien, Josh Robison, and seminar participants at Aarhus University for their helpful comments. We thank Allie Fredendall for research assistance. We also thank the Northwestern Office of Undergraduate Studies and the Danish Social Science Research Council (grant 275-07-0179) for financial support.
582; Hetherington 2009, 429), we nonetheless turn to the more fundamental question of how elite polarization affects the nature of citizen decision making.

We theorize and find, with two experiments on immigration and energy, that elite polarization dramatically changes the ways citizens form opinions. This change occurs because polarization stimulates partisan motivated reasoning, which in turn generates decision making that relies more on partisan endorsements and less on substantive arguments. We discuss the consequences of this shift in decision-making criteria for understanding the nature of public opinion. We also consider the implications of these findings for normative debates about "quality opinions" and more general discussions about polarization and democratic competition. ${ }^{1}$

\section{FRAMING AND PARTY COMPETITION}

Our goal is to assess the impact of elite polarization on citizen decision making. To do so, we employ a counterfactual: We compare the decisions citizens reach in the presence of competing arguments made in a polarized environment against those made in less polarized environments (see Mansbridge 1983, 25). Our central question is, do opinions formed under conditions of elite polarization differ from those formed sans polarization? We specifically compare the role of perhaps the two most widely used types of information on which citizens base political decisions: substantive arguments (of varying types or "strengths") in the form of distinct issue frames and partisan cues. We discuss each in turn.

\section{Framing}

We operationalize "arguments" as directional issue or emphasis frames. Few topics have been studied as

\footnotetext{
${ }^{1}$ Others explore how competition influences decision making, and we build on some of this work in what follows (e.g., Boudreau n.d.; Petersen, Slothuus, and Togeby 2010; Sniderman and Theriault 2004).
} 
extensively in the field of political communication (e.g., Chong and Druckman 2011; n.d.). Frames refer to alternative conceptualizations of an issue or event. A framing effect occurs when "in the course of describing an issue or event, a speaker's emphasis on a subset of potentially relevant considerations causes individuals to focus on these considerations when constructing their opinions" (Druckman and Nelson 2003, 730). An oft-cited example is that if a speaker describes a hate group rally in terms of free speech, then the audience will subsequently base its opinions about the rally on free speech considerations and support the right to rally. In contrast, if the speaker uses a public safety frame, the audience will base its opinions on public safety considerations and oppose the rally (Nelson, Clawson, and Oxley 1997).

A number of studies over the past quarter-century show that framing effects can substantially shape opinions. This work isolates a variety of factors that moderate the impact of a given frame. One of the most important factors is a frame's strength. As with the psychological attitude literature on argument strength (e.g., O'Keefe 2002, 147, 156), frame strength is a relative construct that refers to individuals' perceptions of what makes a compelling argument. Scholars typically assess frame or argument strength by providing respondents with alternative frames/arguments and then asking them to rate the "effectiveness" or applicability of each (e.g., Aarøe 2011; Chong and Druckman 2007; 2010; Druckman 2010; Druckman and Leeper 2012a; O'Keefe 2002). ${ }^{2}$ Concerning a hate group rally, for instance, these frames or arguments could involve considerations of free speech, public safety, public litter, traffic problems, the community's reputation, or racism. A frame is deemed relatively stronger than another if it receives a significantly higher rating of effectiveness or applicability (for detailed discussion, see Chong and Druckman 2007). Different frames on each side might be relatively strong or weak when compared to one another. For example, individuals likely perceive the public safety frame to be a stronger argument against a hate group's rally than an alternative "con" frame that argues that the rally should not be held because it will result in litter in the streets.

If two opposing frames are of equal strength, their effects on an opinion tend to cancel out (Chong and Druckman 2007; Druckman 2004; Jerit 2009; Sniderman and Theriault 2004). Perhaps more interesting is what happens when frames are not evenly matched. A growing research literature shows that strong frames, when used in isolation, move opinions. More importantly, strong frames win out when pitted against relatively weak frames, even if the weak frame is repeated. For example, Druckman (2010) pre-tested frame strength on the issue of a publically funded

\footnotetext{
${ }^{2}$ Another dimension of strength is whether the consideration emphasized in the frame is "available," meaning that individuals are able to connect a given consideration (e.g., free speech) to the issue at hand (e.g., the hate group rally). When necessary (e.g., when it is not evident that considerations are relevant), availability is assessed by asking respondents to list what considerations come to mind when they think of the issue.
}

casino and found that strong frames included the (positive) economic implications and (negative) social costs of building the casino. Pretesting also demonstrated that weak frames included the (positive) entertainment value and (negative) moral implications surrounding the casino's construction. When another group of respondents encountered a mix of these frames, only the strong frames affected their opinion (e.g., a single exposure to the strong economic frame moved opinion by $41 \%$ ), even in the face of multiple negative moral value frames (also see Aarøe 2011). These results are sensible insofar as the frames people find strong do in fact dominate. This leads to our first hypothesis, which echoes the aforementioned work:

Hypothesis 1: When presented with opposing strong frames, individuals' opinions will not be moved by either frame. When presented with a strong frame on one side (e.g., pro) and a weak frame on the other side (e.g., con), individuals' opinions, if affected, will be moved only by the strong frame.

We added the "if affected" caveat to Hypothesis 1 because if individuals have very strong prior opinions on an issue, they are unlikely to be persuaded in any direction (e.g., Brewer 2001).

We briefly mention that we do not necessarily equate "strong" frames with more normatively desirable opinions-particularly because strength is based on perceptions and not normatively derived criteria per se. In our conclusion, we discuss the normative implications of relying on strong frames as opposed to other criteria. For now the question is whether parties, particularly when polarized, influence which types of frames, if any, that people follow. Do party endorsements matter when frames are of different strengths? Does polarization influence this process?

\section{Party Competition}

Even though most frames enter political discourse via political actors (e.g., parties, interest groups), most framing studies have provided study respondents with either unattributed frames or frames attributed to a news organization. Only a few studies have explored how frames from parties influence citizens. The modal finding of these studies is that party source does matter. For example, Slothuus (2010) reports that, when parties switch frames, their members follow (also see Nicholson 2011), although not blindly because partisans also incorporate their own preexisting values. Slothuus and de Vreese (2010) find that party-sponsored frames have greater influence on issues where the parties conflict. These studies, however, do not explore competitive framing environments or vary frame strength (or the substance of distinct arguments more generally), and they do not directly account for different partisan environments (e.g., polarized or not).

Perhaps surprisingly, a similar assessment can be made of the long-standing literature on party cues and endorsement effects. (We use the terms "party cue" and "party endorsements" interchangeably, although we recognize that an endorsement is only one type of cue.). Although scholars have long acknowledged cues 
as central to opinion formation, little existing work explores how citizens grapple with party cues in the presence of substantive information. As Bullock (2011, 496) explains, "In spite of numerous claims about the relative influence of policy attributes and positiontaking by party elites [i.e., party endorsements], direct evidence is slight because few studies directly compare the effects of these variables." He continues, noting that "in political debate, cues and frames almost always appear together: Party elites rarely take a position without trying to frame it in a way that will garner support for it" (511). Bullock (2011) reviews the relevant literature (e.g., Arceneaux 2008, Druckman et al. 2010) and tests the effects of party cues versus policy arguments by varying the availability of cues and content. He finds that party cues have an effect, but do not overwhelm content. He concludes that "party cues are influential, but partisans ... are generally affected at least as much and sometimes much more-by exposure to substantial amounts of policy information" $(2011,512)$.

Although these results are telling, they are not sufficient to address our question. We need to introduce two variations that Bullock did not address: (1) variations in argument type (e.g., frame strength) and (2) variations in partisan polarization. By doing so we can examine the conditions under which party cues dominate, regardless of frame strength, as well as the conditions in which frame strength is the more important factor (also see Nicholson 2011).

To address how partisan polarization affects the relative influence of party cues and substantive arguments on opinion formation, we draw on the theory of partisan motivated reasoning. ${ }^{3}$ Motivated reasoning refers to the tendency to seek out information that confirms prior beliefs (i.e., a confirmation bias), view evidence consistent with prior opinions as stronger or more effective (i.e., a prior attitude effect), and spend more time arguing and dismissing evidence inconsistent with prior opinions, regardless of objective accuracy (i.e., a disconfirmation bias). ${ }^{4}$ These biases influence the reception of new information and may lead individuals to "reason" their way to a desired conclusion. For example, consider a George W. Bush supporter who receives information suggesting that the president misled voters about the Iraq war. Given these biases, this supporter

\footnotetext{
${ }^{3}$ We recognize that there are two (nonexclusive) competing theories of how party sponsorship may influence opinions. First, party sponsorship could work as a simple cue that people follow, with content ignored entirely. Second, sponsorship could serve as a perceptual anchor that shades the interpretation of information. We opt for the latter approach here (see Petersen et al. n.d., for some direct evidence), and we believe that some of the evidence we offer (regarding assessment of argument content) is more consistent with the motivated reasoning approach. That said, we recognize that our results do not rule out the simple cue approach. This is not a problem per se, because our interest lies in uncovering the effects of polarization on citizen decision making and not in isolating the precise psychological mechanism at work.

${ }^{4}$ We employ the term "motivated reasoning," but this should be viewed as synonymous with Taber and Lodge's (2006) "motivated skepticism" and Lavine, Johnston, and Steenbergen's (2012) "partisan perceptional screen." We also focus on information evaluation rather than information seeking (for evidence on information seeking, see Druckman et al. 2012).
}

is likely to interpret this information as either false or as evidence of strong leadership in times of crises. Motivated reasoning will likely lead this supporter and others like him or her to become even more supportive of Bush (e.g., Jacobson 2008). This same behavior also takes place in the presence of partisan cues that anchor reasoning (e.g., Bartels 2002; Goren, Federico, and Kittilson 2009). For instance, individuals interpret a policy in light of existing opinions concerning the policy's sponsor. Thus, a Democrat might view a Democratic policy as effective (e.g., a new economic stimulus plan) and support it, whereas he or she would see the same policy as less effective and perhaps even oppose it if not endorsed by Democrats or if sponsored by Republicans (e.g., Druckman and Bolsen 2011). Similarly, Democrats (Republicans) may view economic conditions favorably during a Democratic (Republican) administration even if they would view the same conditions negatively if Republicans (Democrats) were in power (e.g., Bartels 2002; Lavine, Johnston, and Steenbergen 2012). ${ }^{5}$

In short, partisan motivated reasoning theory suggests that partisans will view their party's frame as more effective than a frame not sponsored by their party or a frame sponsored by the other party. This theory also suggests that partisans will more likely be moved by their own party's frame, regardless of its strength. This leads to two hypotheses. (In our hypotheses, it is less interesting to examine when an individual's own party offers a strong frame because in that case both pieces of information - the party sponsor and the frame strength-push in the same direction.)

\begin{abstract}
Hypothesis 2: When partisans receive a frame, regardless of its strength, sponsored by their party and a conflicting frame, regardless of its strength, sponsored by the other party, they will view their own party's frame as more effective and the other party's frame as less effective.
\end{abstract}

\section{Hypothesis 3: When partisans receive a frame, regardless of its strength, sponsored by their party and a conflicting frame, regardless of its strength, sponsored by the other party, they will be more likely to move in the direction of their party's frame than in the direction of the other party's frame. ${ }^{6}$}

A number of factors moderate partisan motivated reasoning, including motivation itself. When individuals are highly motivated to form accurate opinions, they tend to focus on substance regardless of their partisanship and/or prior opinions (e.g., Kunda 1990, 485; also see Nir 2011; Prior 2007). Even so, most evidence to date suggests that, on political issues, individuals generally lack such motivation and instead fall back on

\footnotetext{
${ }^{5}$ This coheres with social identity theory-indeed, motivated reasoning should be driven by individuals' desire to be loyal to and consistent with their own group and to maximize difference with the outgroup. Partisan groups are clearly important to political categorization (Nicholson 2012; Smith et al. 2005).

${ }^{6}$ It is implied that we expect perceptions of frame effectiveness to mediate the process by which the frame will influence overall attitude. Yet, we do not offer a formal prediction because, as will be clear, the nature of our design-in which perceptions and attitudes are measured simultaneously-means that directly testing this type of mediational prediction is not possible.
} 
partisan motivated reasoning when interpreting new information. Taber and Lodge $(2006,767)$ conclude, "despite our best efforts to promote the even-handed treatment of policy arguments in our studies, we find consistent evidence of directional partisan bias.... Our participants may have tried to be evenhanded, but they found it impossible to be fair-minded."

That said, one factor that does moderate partisan reasoning is the strength of partisan identity-those who possess strong partisan identities are more inclined to base their assessments of frames entirely on their partisan priors. In contrast, weaker partisans are less skewed by their identities and are more likely to respond to content. Lavine, Johnston, and Steenbergen (2012) present substantial evidence of this weakening effect, concluding that partisan "ambivalence undercuts the judgmental confidence that citizens typically derive from partisan cues, [and] they should turn away from these perceptual anchors and pay more attention to the particulars" (chapter 5: 2; also see Druckman, Fein, and Leeper 2012; Redlawsk 2002; Taber and Lodge 2006).

The evidence presented by Lavine, Johnston, and Steenbergen (2012) suggests that, when a stimulus prompts partisan ambivalence, motivated reasoning should vitiate and a focus on the substance of the frame should increase. The stimulus we focus on is elite partisan polarization (as mentioned, elite polarization is a measurement concept distinct from citizen polarization; see Fiorina and Abrams 2008). We follow convention and define elite polarization as having "two components: the ideological distance between the parties, and the ideological homogeneity of each party" (Levendusky 2010, 118). As party elites polarize and that polarization is relayed to citizens, partisans should become less ambivalent about (i.e., more sure of) their own party identity. This is the type of dynamic uncovered by Iyengar, Sood, and Lelkes (2012) who find that negative campaigning between parties, which stems from increased polarization, is "an especially important contextual factor that heightens the salience of partisan identity." Similarly, Dancey and Goren (2010, 686) explain, "When partisan elites debate an issue and the news media cover it, partisan predispositions are activated in the minds of citizens and subsequently constrain their policy preferences." Nicholson (2012, 52, 55) states, "In the American political system, one's political identity typically means one's partisan identity (see Green, Palmquist, and Schickler 2002), especially in an era of partisan polarization.... In an environment characterized by intergroup disagreement, the desire to seek difference with the outgroup will likely be strong." 7 And Levendusky (2010,114-15) adds, "When elites are polarized, they send voters clearer signals about where they stand on the issues of the day....

\footnotetext{
${ }^{7}$ Slothuus and de Vreese $(2010,637)$ state, "In contrast to political consensus, party conflict signals that partisan values are at stake and emphasizes differences between parties. In such conflict situations, citizens' partisanship should to be more salient to them and hence more likely be used in judging the applicability of framings of the issue."
}

As voters follow these party cues on multiple issues, they begin to hold more consistent attitudes." In sum, under conditions of polarization, partisan identification becomes stronger and less ambivalent, leading to increased motivated reasoning (and stronger party cue effects); see Nicholson $(2012,54-5)$ for further psychological discussion. ${ }^{8}$ We should thus see stronger motivated reasoning effects in the polarized conditions than in the non-polarized environment.

Hypothesis 4: In a polarized environment, when partisans receive a frame, regardless of its strength, sponsored by their party, and a conflicting frame, regardless of its strength, sponsored by the other party, they will view their own party's frame as more effective and the other party's frame as less effective-to a greater extent than they do in a non-polarized environment (and/or a nonparty cue environment).

Hypothesis 5: When partisans receive a frame, regardless of its strength, sponsored by their party and a conflicting frame, regardless of its strength, sponsored by the other party, they will be more likely to move in the direction of their party's frame than in the direction of the other party's frame-to a greater extent than they do in a non-polarized environment (and/or a nonparty cue environment). ${ }^{9,10}$

Our final hypothesis concerns the importance that a respondent attributes to his or her updated opinion after receiving the frame. When individuals engage in motivated reasoning, their goal is to confirm an opinion they already hold (Taber and Lodge 2006). They therefore view new information as bolstering their prior opinion, and this added evidence boosts the importance of that opinion to them (e.g., via increased confidence in the opinion). In contrast, when acting against a prior belief (e.g., generated by the partisan perceptional screen), people may become unsure about what to think and thus view the opinion as less personally important (e.g., Brader 2006, chaps. 4-5). Our expectation of increased attitude importance with partisan motivated reasoning coheres with social psychological work in which social identification is seen as "one of the antecedents of attitude importance" (Smith et al. 2005, 168; Wyer 2010). Specifically, Smith et al. $(2005,168)$ report that when individuals perceived that an "issue was highly relevant to the group under consideration, they reported that their own attitudes were more personally important."

\footnotetext{
${ }^{8}$ We build on Lavine, Johnston, and Steenbergen (2012) given their compelling evidence regarding attitude ambivalence; however, in theory, other aspects of partisan identity can be affected via polarization (e.g., importance of that identity, relevance of that identity, etc.).

${ }^{9}$ We again avoid a formal mediational prediction.

${ }^{10}$ We previously noted that our predictions could be consistent with a theory of partisan cue taking rather than partisan motivated reasoning. In this regard, it could be that the existence of polarization indicates that the parties feel more strongly about the issue (are more certain about their positions). This kind of certainty then makes the cue stronger because the source is more certain. We thank Gabe Lenz for this point (April 17, 2011, personal communication). As mentioned, although we believe our motivated reasoning approach offers a fuller, more compelling explanation, it may be that the process at work is cue taking, yet that does not alter our ultimate substantive conclusions.
} 
Hypothesis 6: Partisans will view their opinions as increasingly important when receiving a frame with their partisan sponsor (versus a frame without their partisan sponsor) and, even more so, when this occurs in polarized conditions. $^{11}$

\section{EXPERIMENTAL TESTS OF PARTISAN POLARIZATION AND FRAMING}

We conducted two experiments to test our hypotheses via the internet, with a sample drawn to be representative of the U.S. population, during the spring of 2011. ${ }^{12}$ Both experiments appeared on the same survey.

One concern in any experiment concerning partisanship is that asking about party identification primes respondents to base attitudes on that identity. We were thus fortunate that our survey experiments avoided this problem by coming as part of a panel that started in the summer of 2010. Respondents reported their partisan identification by responding to the item, "Generally speaking, which of the options on the scale below best describes your party identification?" on a 7-point fully labeled scale from strong Democrat to strong Republican. They also reported other demographic information on this prior wave. ${ }^{13}$

We focused our analyses on partisans; that is, individuals identifying with or leaning toward either party $(N=646)$. As with Levendusky's $(2010,120)$ experiment on partisan polarization, we excluded pure independents (also see, e.g., Bullock 2011). This approach is typical because independent leaners are similar to partisans in their vote choice and policy opinions (e.g., Lascher and Korey 2011). After excluding independents, our sample consisted of $53 \%$ Democrats and $47 \%$ Republicans.

We next describe our experimental design, discussing the issues used in the experiments, the frames we employed, our polarization manipulation, our precise experimental conditions, and our main dependent measures.

\footnotetext{
$\overline{11}$ We recognize that importance, like our aforementioned ambivalence construct, is a dimension of attitude strength. As Visser, Bizer, and Krosnick (2006) make clear, different types of attitude strength are relevant in distinct situations and at varying points in the reasoning process. It is for this reason that we looked at different dimensions and did not attempt to envelope them under a general rubric of strength.

12 We contracted with a survey research company (Bovitz Inc.) to collect the data. The sample was drawn from a panel of respondents who had opted in to complete online surveys. The panel was originally developed based on a random-digit-dial (RDD) telephone survey, where to enter the panel a respondent needed to have access to the internet; in this sense, it is a nonprobability sample in the same way as those taken by firms such as Polimetrix are nonprobability samples. The panel has continued to grow based on ongoing RDD recruiting and referrals. From the panel, which has approximately 1 million members, a given sample is drawn using a matching algorithm (based on likely response rates) to ensure that those screened to qualify for the survey constitute a sample that demographically represents the United States.

${ }^{13}$ Demographics of the sample are available from the authors; $45 \%$ of $\mathrm{t} 1$ participants responded at $\mathrm{t} 2$, which is a fairly standard rate.
}

\section{Policy Issues}

One experiment focused on an energy policy proposal: drilling for oil and gas. The second experiment examined immigration policy, specifically the DREAM Act-which stands for the Development, Relief, and Education for Alien Minors Act. These two issues share several features that make them well suited for testing our hypotheses. First, both received attention in policy debates in the United States prior to our study and thus are meaningful and relevant issues. Although drilling for oil in the ocean began in the late $1800 \mathrm{~s}$ and became widely used in the mid-twentieth century the issue received substantial attention in U.S. politics during 2010. In March of that year, President Obama announced that the United States would allow drilling for oil and gas off the Atlantic Coast and in the eastern Gulf of Mexico. He suggested it was necessary to sustain economic growth. Then, on April 20, 2010, the Deepwater Horizon oil spill, the worst offshore oil spill in U.S. history, occurred in the Gulf of Mexico. Consequently, the Obama administration shifted policy and decided that it would not open up new areas of the eastern Gulf and Atlantic seaboard to drilling, at least for seven years. Similarly, the DREAM Act, a legislative proposal first introduced in the U.S. Senate in 2001, has been regularly debated in the U.S. Congress and several state legislatures over the last decade. Although the bill has been proposed in various forms, its core is the creation of a pathway to citizenship for undocumented immigrants living in the United States, provided they entered the United States before age 16, graduated from high school, have "good moral character," and have completed at least two years of college or served at least two years in the U.S. military. ${ }^{14}$

Second, we suspect that, although these issues are topically relevant, the public's opinions on them are not crystallized and, indeed, are somewhat conflicted. As we discuss later in further detail, this conflict stems from the existence of many competing considerations on each issue (Krauss and Broder 2012). As with most other work, we opted for such conflict because it means there is room for movement in our experiments (see, e.g., Chong and Druckman 2010, 667; Druckman and Leeper 2012b; Levendusky 2010, 119-20; Nicholson 2011; Slothuus 2011).

Third, it was important that we chose issues on which the parties do not consistently hold dramatically different positions. ${ }^{15}$ Doing so allows our experimental prompts to shape the perceived level of partisan

\footnotetext{
${ }^{14}$ In June 2012, President Obama enacted elements of this proposal through an executive order that halted the deportation of undocumented immigrants eligible for the DREAM Act.

15 We also chose issues that were not "owned" by either party to ensure each party had roughly equivalent credibility in discussing an issue. Pew data asking which party does a "better job" at handing a given issue show that, in September 2010, respondents gave Republicans an advantage on immigration with $39 \%$ citing the Republicans, $32 \%$ citing the Democrats, and the others saying both, neither, or don't know. For the question about which party does a better job handling energy, which was asked in March 2011, there is a near split, with $42 \%$ saying the Democrats could do a better job and $37 \%$ favoring the Republicans (Pew Research Center 2010; 2011).
} 
disagreement (i.e., polarization) on these issues. Although Republicans in Congress tend to favor allowing drilling and Democrats in Congress tend to oppose drilling, the partisan divide is often not stark, and members of each party can typically be found on each side of the issue (e.g., often depending on geography; for example, Virginia Democratic Senator Mark Warner strongly supports offshore drilling). Like elites, the public is split on drilling and is not overly driven by partisan predications (Bolsen and Cook 2008). The various versions of the DREAM Act, meanwhile, have been cosponsored and supported by both Democrats and Republicans, although it is the Democrats at the elite level who more consistently offer support. Partisan DREAM Act support at the mass level is even more mixed than on drilling. Unsurprisingly, the two issues on which we focused have been used in prior work that touches on polarization (e.g., Levendusky 2010, on drilling; Nicholson 2012, on immigration).

That said, we recognize that these are issues on which the parties are likely stereotypically connected with given positions, albeit perhaps not strong stereotypes. In this initial foray, we opted not to vary issues in such a way that the parties were either more strongly connected to particular issues or took even more muddled positions-but we recognize that such issue-position variance is a fruitful avenue for future work.

\section{Issue Frames}

Our next task was to select the frames on each issue. We identified the relevant arguments/frames in public debate through a content analysis of media coverage (see Peterson 2011) and examination of prior work on both issues (e.g., Bolsen and Cook 2008; Smith 2002) We selected seven prominent frames for each issue. ${ }^{16}$ Next, we presented 138 nonstudent participants (who were not in the main experiment) with sequential issue descriptions along with brief depictions of the frames/arguments. As with prior work, we asked respondents to evaluate the direction and strength of frames on each policy issue (on 7-point scales ranging from definitely opposed to definitely supportive, and from definitely not effective to definitely effective).

Full details of the pretest results are available from the authors; in the end, we selected four frames for each issue: a strong and weak pro frame (e.g., for drilling, the DREAM Act) and a strong and weak con frame (e.g., opposed to drilling, the DREAM Act). We display our choices in Tables 1a and 1b. For drilling, our strongpro frame emphasized the "economic benefits" of the

\footnotetext{
16 The drilling frames included ones that emphasized the consequences for the economy, foreign dependence, national security, technological development, the ecosystem, regulatory issues, and worker and maritime life. The DREAM frames included ones that emphasized the impact on the beneficiaries, public support, fairness, economic consequences, impact on legal immigrants, surrounding politics, and systematic consequences.
}

\begin{tabular}{|c|c|c|}
\hline & Supportive (Pro) & Opposed (Con) \\
\hline Strong & Economic benefits & $\begin{array}{l}\text { Worker and maritime } \\
\text { life }\end{array}$ \\
\hline Weak & $\begin{array}{l}\text { Technological } \\
\text { developments }\end{array}$ & Regulation \\
\hline
\end{tabular}

TABLE 1b. DREAM Act Frames

\begin{tabular}{lll}
\hline & Supportive (Pro) & Opposed (Con) \\
\hline Strong & Beneficiaries & $\begin{array}{c}\text { Overburdening } \\
\text { the system }\end{array}$ \\
Weak & Public support & Politics \\
\hline
\end{tabular}

practice, including how drilling will increase the oil supply, leading to lower gas prices and the creation of employment opportunities. In contrast, our weak-pro frame suggested that drilling leads to new "technological developments" (e.g., sound migration techniques) that sometimes have more general applications beyond drilling. On the con side, our strong drilling frame focused on the dangers of drilling for "workers and maritime life," whereas our weak-con frame focused on the "regulation" that would come with drilling through government oversight of the process.

For the DREAM Act issue, as displayed in Table 1b, our strong-pro frame emphasized how the young "beneficiaries" would be offered many opportunities (e.g., to go on to become doctors, teachers, and the like), whereas the weak-pro frame focused on "public support" for the act (e.g., many segments of the public support the DREAM Act). On the con side, our strong frame concerned "overburdening the system" due to an increase in illegal immigration (and demands on government services) if the DREAM Act passed, whereas the weak frame put weight on the "politics" underlying the policy's design.

For each of our two issues, pretest respondents perceived each pro frame to be significantly more supportive on the issue than each of the con frames. Moreover, although pretest respondents viewed each strong frame as significantly more effective than each weak frame, they did not see the two strong frames as significantly different from one another in terms of strength (nor were the weak frames statistically distinct from one another in terms of "in"effectiveness). Thus, we are confident that, for each issue, our pro (con) frames differed from one another only in terms of strength (and not direction) and our strong (weak) frames differed from one another only in terms of direction (and not strength). Also, note that on both issues, we did not observe partisan differences in the assessments of the frames.

As we discuss, assigned respondents received a single (strong or weak) pro frame on each issue and a single 
(strong or weak) con frame on each issue. ${ }^{17}$ Before further describing the conditions, however, we turn to the other main factor in our study: partisan cues and polarization.

\section{Partisan Cues and Polarization}

Our hypotheses offer distinct predictions about the impact of strong and weak frames depending on the presence of party cues and the degree of polarization. Of course, a critical baseline is how respondents react to the frames sans partisan endorsements. For this reason, one set of conditions excluded any reference to political parties (i.e., no party cues were present). These conditions allow us to test Hypothesis 1 about reactions to basic frames and serve as a baseline against which to assess the impact of the partisan cues and information about polarization provided in the other conditions.

Two points are relevant for our operationalization of partisan endorsements and polarization. First, we followed Levendusky (2010) in offering multiple competing party cues in all cases-we never offered a frame that receives a party endorsement against another frame sans a party endorsement. This approach is realistic given that each party adopts a position and offers an argument/frame on most issues. It also does not limit our ability to test our hypotheses. Second, also as did Levendusky (2010), we had the parties maintain single positions across all conditions. That is, the Democrats always opposed drilling and endorsed the DREAM Act-albeit using different frames-whereas the Republicans always did the reverse. This is realistic given the parties" "typical" positions (also see Nicholson 2012). Our wording stated, for example, "Democrats in Congress tend to favor ... and Republicans in Congress tend to oppose." We recognized the advantage that would come with having parties flip to unconventional positions (see, e.g., Slothuus 2011), but we decided not to vary party positions because this approach allowed for a feasible number of conditions (without varying party positions our design still included 13 experimental conditions). More importantly, maintaining consistent party endorsements did not constrain our ability to assess our key hypotheses about the impact of party endorsements and polarization (for a similar argument, see Levendusky 2010). In sum, respondents received, on each issue, a weak or strong pro frame and a weak or strong con frame. These frames either came with no party endorsements or with a party endorsement such that the pro (con) drilling frame was always endorsed by Republicans (Democrats) whereas the pro (con) DREAM frame was always endorsed by Democrats (Republicans).

The second aspect of our manipulation varied the level of elite polarization. We again followed Levendusky $(2010,117)$ and told respondents that the partisan elites were either moderate or polarized (i.e., par-

\footnotetext{
${ }^{17}$ Our inclusion of a limited number of frames in the experimental design is realistic because content analyses show that competing sides in policy debates tend to restrict their attention to very few frames on each side (Chong and Druckman 2011; Hänggli and Kriesi 2010).
}

ties were far apart and homogeneous). ${ }^{18}$ In the nonpolarized or moderate conditions, we told participants that "the partisan divide is not stark as the parties are not too far apart" and that "members of each party can be found on both sides of the issue." In contrast, the polarized stimulus stated that "the partisan divide is stark as the parties are far apart" and "most members of each party are on the same side as the rest of their party" (thereby capturing the two aforementioned dimensions of elite polarization). ${ }^{19}$

Our full set of conditions included 13 different scenarios with each respondent randomly assigned to one. The first was a control group (condition 1) that answered the dependent measures, described later, without receiving any other information. We display the 12 treatment conditions in Table 2 (with the cells reporting the $N$ s for each issue; the first $N$ is for the drilling issue). The columns list the mix of frames encountered by a respondent in a given condition-as explained, this mix always involved one pro and one con frame, of varying strengths. The rows report the nature of the partisan endorsement and the specific endorsement for each issue (in the first column of each row). The frames used in the conditions reported in the first row made no reference to party. The conditions in the second row provided partisan endorsements, but these endorsements were preceded by the previously described non-polarized prompt. The conditions in the final row included endorsements along with the polarized scenario. To get a sense of the wording of a specific condition, consider Condition 10 (polarized party endorsements, two strong frames), for the drilling issue, which reads,

There has been a lot of recent discussion about whether to allow drilling for oil and gas off the Atlantic Coast and in the eastern Gulf of Mexico.

Republicans in Congress tend to favor drilling and Democrats in Congress tend to oppose drilling. Moreover,

\footnotetext{
18 As with Levendusky (2010), we did not include conditions with party cues and no polarization manipulation. Such conditions would have allowed us to infer about the "natural" state of the world (e.g., closer to our polarization scenario or non-polarization scenario). Yet, it would have expanded the number of conditions to 17 , and we suspect any such inferences would have limited time and issue generalizability. Our ultimate interest is in polarization versus non-polarized settings, and one can assess independently the extent to which a given time/issue approaches one or the other (see Slothuus 2011).

${ }^{19}$ We thus operationalized polarization in a different way than did Levendusky, who presented respondents with a picture of the issue positions of members of Congress as being either polarized or not There are two reasons for our approach. First, we found that words more accurately mimic the type of information respondents may receive (e.g., via a media report). Second, such ecological validity was important in our case because we suspect such information prompts a distinct processing approach. The polarization text may stimulate citizens to engage in directional processing to be consistent with fellow partisans (for a similar approach in a distinct domain, see Boiney, Kennedy, and Nye 1997, 8). Using the non-polarized text relieves partisans of such a directional goal and may generate more memory search (see Redlawsk 2002). To be clear, we did not opt for these manipulations so as to explicitly skew the likely results in the direction of particular types of processing; rather, we wanted to most accurately mimic the type of information encountered, which we believe has precise processing implications.
} 


\section{TABLE 2. Experimental Conditions}

\begin{tabular}{|c|c|c|c|c|}
\hline & $\begin{array}{l}\text { Pro Strong } \\
\text { Frame } \\
\text { Con Strong } \\
\text { Frame }\end{array}$ & $\begin{array}{l}\text { Pro Strong } \\
\text { Frame } \\
\text { Con Weak } \\
\text { Frame }\end{array}$ & $\begin{array}{l}\text { Pro Weak } \\
\text { Frame } \\
\text { Con Strong } \\
\text { Frame }\end{array}$ & $\begin{array}{l}\text { Pro Weak } \\
\text { Frame } \\
\text { Con Weak } \\
\text { Frame }\end{array}$ \\
\hline $\begin{array}{l}\text { No-party Endorsements } \\
\text { Non-Polarized Party } \\
\text { Endorsements }\end{array}$ & $\begin{array}{c}(2) \\
N(\text { drilling })=48 \\
N(\text { DREAM) }=46 \\
(6) \\
N=51\end{array}$ & $\begin{array}{l}(3) \\
\mathrm{N}=55 \\
\mathrm{~N}=55 \\
(7) \\
\mathrm{N}=49\end{array}$ & $\begin{array}{l}(4) \\
N=51 \\
N=49 \\
(8) \\
N=50\end{array}$ & $\begin{array}{c}(5) \\
\mathrm{N}=46 \\
\mathrm{~N}=50 \\
(9) \\
\mathrm{N}=51\end{array}$ \\
\hline $\begin{array}{l}\text { For drilling } \rightarrow \\
\text { Rep }=\text { Pro } \\
\text { Dem = Con }\end{array}$ & $N=51$ & $N=44$ & $N=56$ & $\mathrm{~N}=50$ \\
\hline \multicolumn{5}{|l|}{$\begin{array}{l}\text { For DREAM } \\
\text { Rep }=\text { Con } \\
\text { Dem }=\text { Pro }\end{array}$} \\
\hline $\begin{array}{l}\text { Polarized Party } \\
\text { Endorsements }\end{array}$ & $\begin{array}{c}(10) \\
N=54\end{array}$ & $\begin{array}{c}(11) \\
N=49\end{array}$ & $\begin{array}{c}(12) \\
N=45\end{array}$ & $\begin{array}{c}(13) \\
N=50\end{array}$ \\
\hline $\begin{array}{l}\text { For drilling } \rightarrow \\
\text { Rep }=\text { Pro } \\
\text { Dem = Con }\end{array}$ & $N=52$ & $N=52$ & $\mathrm{~N}=50$ & $N=44$ \\
\hline $\begin{array}{l}\text { For DREAM } \rightarrow \\
\text { Rep }=\text { Con } \\
\text { Dem = Pro }\end{array}$ & & & & \\
\hline
\end{tabular}

the partisan divide is stark as the parties are far apart. Also, not only do Republicans tend to be in favor and Democrats opposed, but most members of each party are on the same side as the rest of their party.

The main argument for those in favor of drilling is that drilling increases our oil supply, which leads to lower gas prices. It also generates employment opportunities and development.

The main argument for those opposed to drilling is that workers are required to learn new skills in order to protect themselves against the dangers of drilling. Marine life also must adapt to survive in the face of site construction and drilling.

To see how polarization and frame strength varied between conditions, compare this with Condition 7 (nonpolarized party endorsements, strong pro frame, weak con frame) on the same issue, which reads,

There has been a lot of recent discussion about whether to allow drilling for oil and gas off the Atlantic Coast and in the eastern Gulf of Mexico.

Republicans in Congress tend to favor drilling and Democrats in Congress tend to oppose drilling. However, the partisan divide is not stark as the parties are not too far apart. Also, while Republicans tend to be in favor and Democrats opposed, members of each party can be found on both sides of the issue.
The main argument for those in favor of drilling is that drilling increases our oil supply, which leads to lower gas prices. It also generates employment opportunities and development.

The main argument for those opposed to drilling is that government regulators oversee the drilling. These regulatory agencies recently have expressed being overwhelmed by oversight tasks.

Stimuli in Conditions 2-5 made no reference to parties and left out the paragraph on party endorsements. We purposely avoided overly blunt party cues by decoupling the cues from the arguments. Hence, we presented party cues and frames as potentially competing information to illuminate what information people use. We also provided some substantive information in the frames rather than strict endorsements because detailed information is important when studying relative partisan cue effects (Bullock 2011). The full wording of the other conditions appears in Appendix A.

We assigned all participants to conditions on both issues, and they always received information about drilling first. Participants were also assigned to the same conditions on each issue, because we worried that varying the extent of polarization would seem disorienting (see Slothuus 2011) and would also increase the likelihood of experimental spillover effects (Transue, Lee, and Aldrich 2009, 160). ${ }^{20}$

\footnotetext{
${ }^{20}$ As we show, the dynamics are very similar across issues, and hence
} there is little reason to assume/believe that the accumulation of 


\section{Measures}

We included appropriate measures to test each of our hypotheses, as well as measures for variables, shown in prior work to affect energy or immigration attitudes. In what follows, we do not report results with these other variables, because they do not affect our main results; suffice it to say that those results echo prior work on energy and immigration. ${ }^{21}$

Our main dependent variables involved support for drilling and support for the DREAM Act, and we used question wordings from prior national surveys on these issues. The drilling item asked, "Given this information, to what extent do you oppose or support drilling for oil and gas off the Atlantic Coast and in the eastern Gulf of Mexico?," with answers on a fully labeled 1 to 7 scale ranging from strongly oppose to strongly support. The DREAM Act support variable similarly asked (with an analogous 7-point scale), "Given this information, to what extent do you oppose or support the DREAM Act?" These measures allowed us to test Hypotheses 1, 3 , and 5 concerning the relative impact of issue frames, partisan cues, and polarization on overall opinion. All the DREAM Act measures came after the DREAM Act treatments, which followed the drilling treatments and measures.

Testing Hypotheses 2 and 4 required a measure asking respondents to assess the effectiveness of the frames to which they were exposed. We followed others (e.g., Druckman and Bolsen 2011) and asked, for each issue, "How effective or ineffective did you find the main argument opposed to drilling [the DREAM Act]?" with response options offered on a 1 to 7 scale ranging from completely ineffective to completely effective. We then asked, using an analogous scale, "How effective or ineffective did you find the main argument in favor of drilling [the DREAM Act]?"22

Finally, to test Hypothesis 6 about opinion importance, we asked respondents, after they reported their overall support opinions for each issue, this question: "How important to you is your opinion about drilling [toward the DREAM Act] (e.g., how strongly do you feel about your opinion)?" As with the other questions, respondents could provide an answer on a 1 to 7 scale from extremely unimportant to extremely important (see Visser et al. 2006).

partisan stimulus over time reinforced its effects (i.e., if that would have been the case, partisan differences should increase in magnitude to the second experiment).

${ }^{21}$ For example, Republicans were more supportive of drilling, and Democrats were more supportive of the DREAM Act. Other measured variables include basic demographics as well as ideology, relevant values (e.g., environmental values or ethnocentrism), national economic retrospective evaluations, media use, general political knowledge, and domain-specific knowledge. Full details are available from the authors.

22 We recognize that, as with others (e.g., Druckman and Bolsen 2011; Taber and Lodge 2006) who have taken similar approaches of asking overall opinion and argument effectiveness questions in tandem, we risk the possibility of contamination. That said, our pretest results offer additional evidence on frame strength from a distinct sample, and the problem is less severe insofar as we do not explore mediational processes that would directly make the possible confound relevant.

\section{RESULTS}

We first present the results regarding overall support for drilling and the DREAM Act (i.e., Hypotheses 1,3, 5 ) by charting the percentage change in opinion, by condition, relative to the control group (which answered the two issue support questions without encountering other information). The means and standard deviations for each condition appear in Appendix B (Tables B.1 and B.2). Our approach is appropriate because we posited the control group as a baseline for our hypotheses (at least implicitly). We also compare across treatment conditions, when necessary, to assess specific hypotheses. Finally, because our results on both issues are very similar to one another, we present them in tandem-that is, we go through each hypothesis on both issues rather than sequentially presenting results on the issues. $^{23}$

Figures 1-3 present the change in opinion across each of our 12 treatment conditions (panel A displays drilling results and panel B displays DREAM Act results; "Stg" indicates strong frames and "Wk" indicates weak frames). In each figure, we separate Democrat and Republican respondents to detect the different effects of party endorsements hypothesized for each set of partisans. Figure 1 presents results for the conditions that did not include party endorsements. It allows us to test Hypothesis 1 that frames of equal strength should cancel, but that strong frames overwhelm weak frames. This is exactly what we found on both issues. For example, Figure 1a shows that, for both types of partisans, exposure to the pro-strong and con-strong frames (Condition 2) did not cause a significant change in opinion, with opinions only moving slightly more than $2 \%$ for Democrats and about $5 \%$ for Republicans (significance levels are indicated with asterisks). The same was true with pro-weak and con-weak exposure (Condition 5). Yet, when the pro frame was strong (economic benefits) and the con frame was weak (regulation; Condition 3), opinions for both Democrats and Republicans became dramatically more supportive. In other words, the strong economic argument, when pitted against the weak regulation frame, increased support for drilling by nearly $19 \%$ among Democrats and $14 \%$ among Republicans. Analogously, opinions moved significantly in the other direction when the pro frame was weak (technological developments) and the

\footnotetext{
${ }^{23}$ We included a manipulation check to ensure that participants registered the parties' endorsements (i.e., we asked respondents, toward the end of the survey, if they recalled the pro and con positions of the parties on each issue). On the drilling issue, on average $89 \%$ of participants correctly recalled the pro and con positions of the parties (ranging from $85 \%$ to $94 \%$ across the eight conditions with party cues), and on the immigration issue $87 \%$ correctly recalled party positions. We also found no significant difference in recall accuracy based on whether the respondent was in a polarized or nonpolarized condition. We further asked respondents across conditions the extent to which they thought the parties were polarized, and the results confirmed that our polarization conditions prompted significantly higher perceptions of polarization. Finally, we asked people to report the "importance" of their party identification and found significantly higher scores in the polarization conditions, suggesting that polarization did strengthen partisan identification.
} 


\section{FIGURE 1a. Drilling Support, No Party Cues}

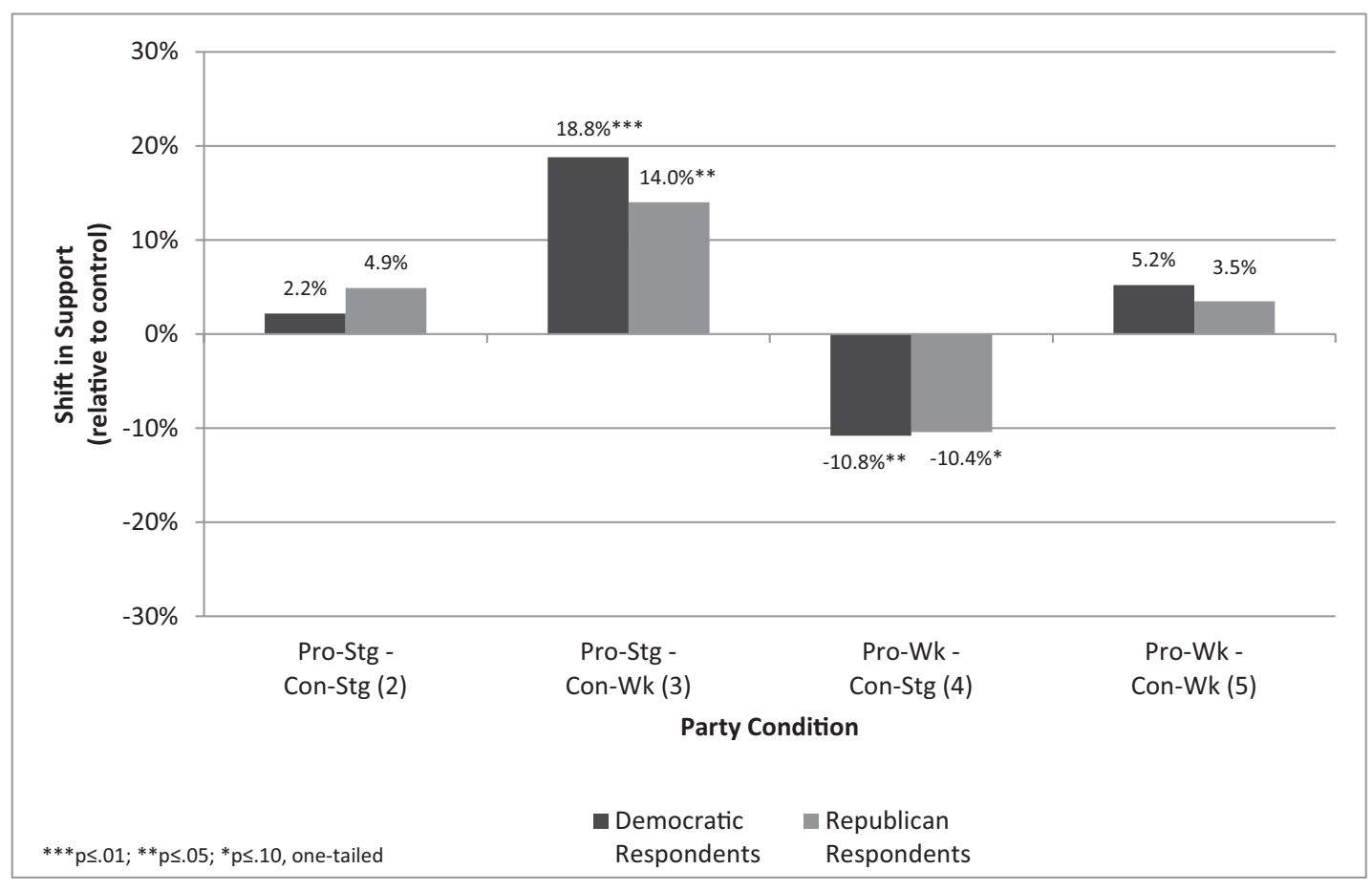

\section{FIGURE 1b. DREAM Act Support, No Party Cues}

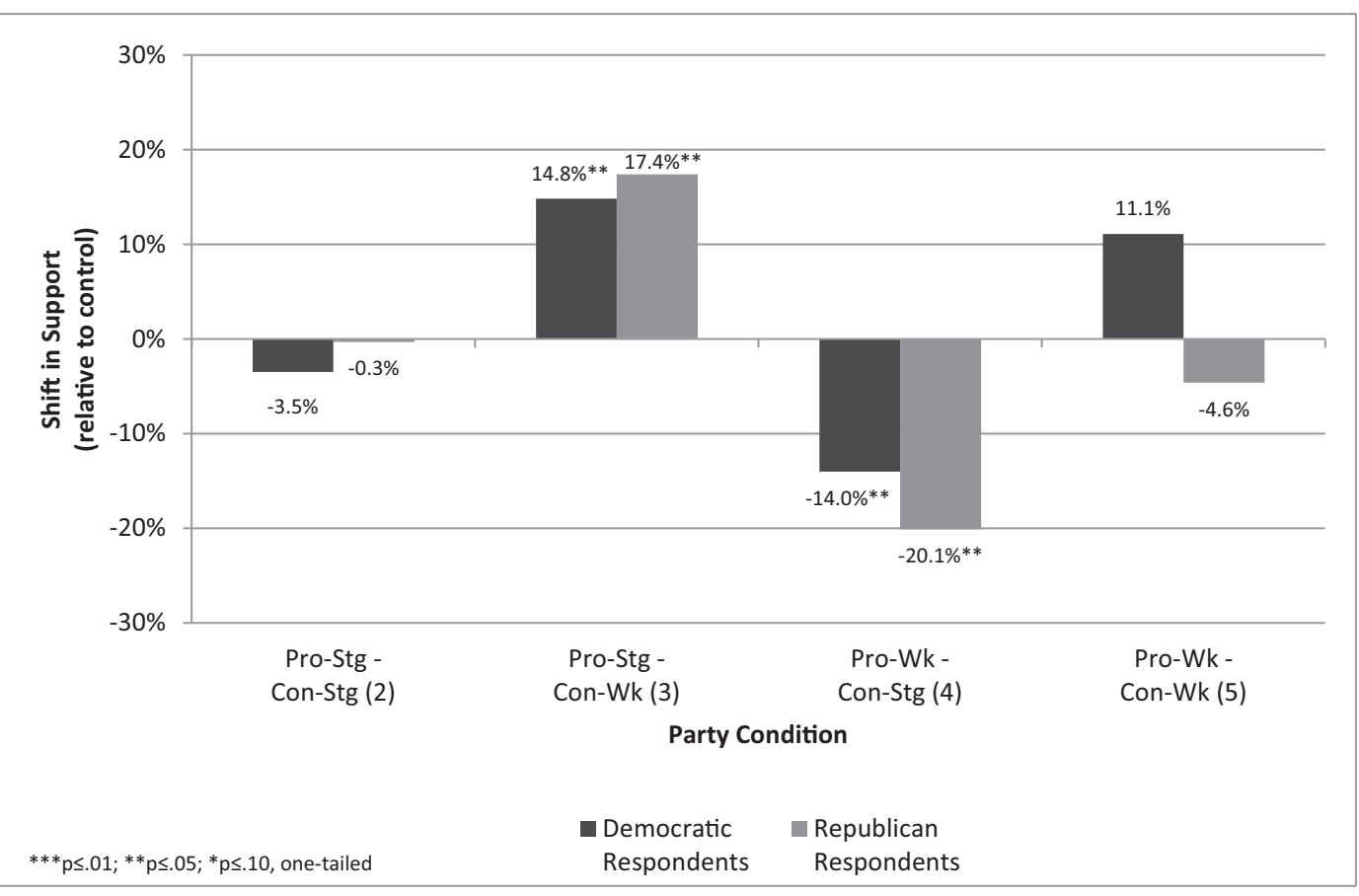




\section{FIGURE 2a. Drilling Support, Non-Polarized Party Cues (Republicans Pro, Democrats Con)}

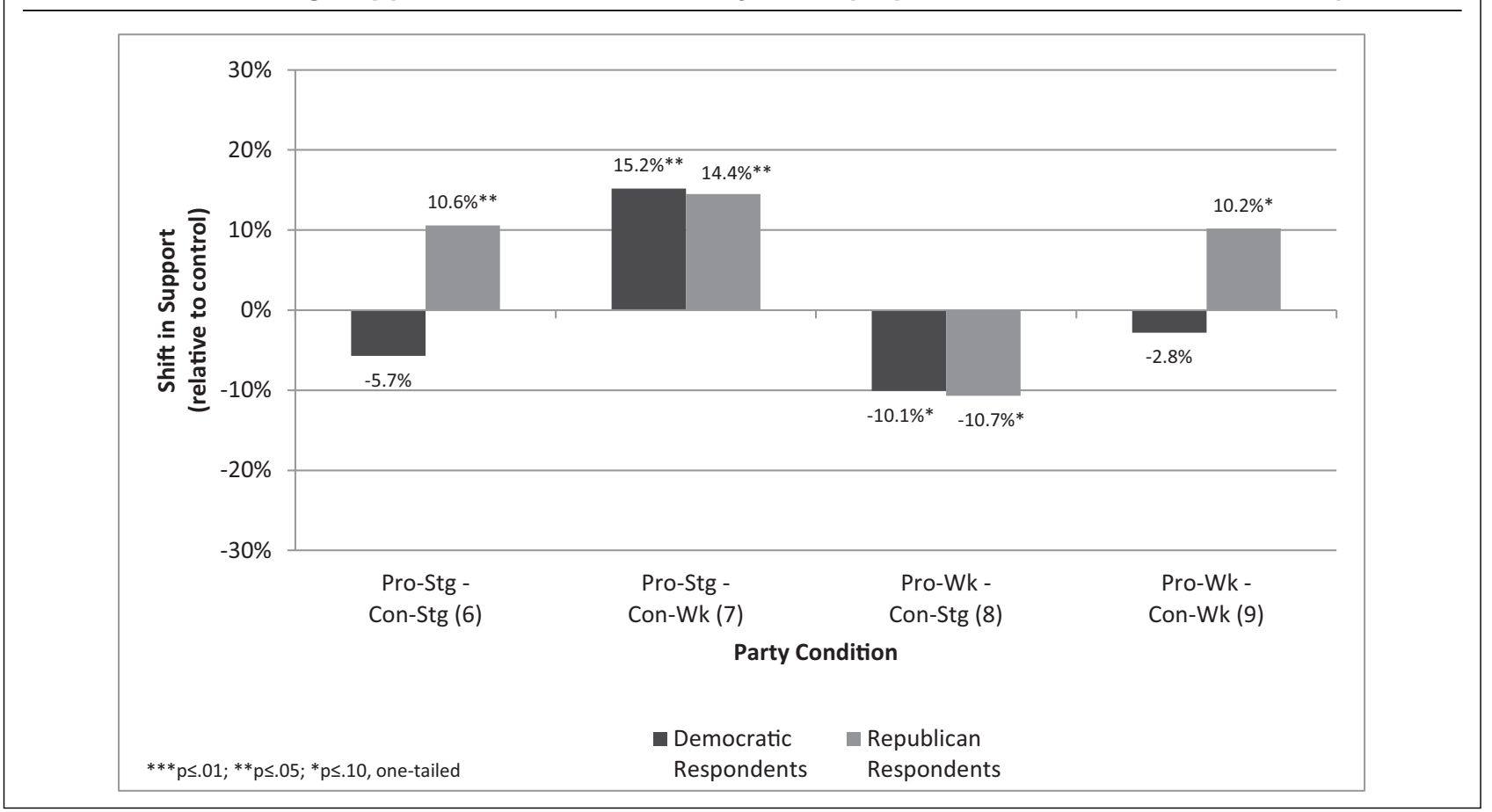

con one was strong (worker and maritime life; Condition 4). We found virtually identical results in Figure 1b on the DREAM Act. For example, on receiving the pro-strong beneficiaries frame along with the weakcon politics frame (Condition 3), Democratic support increased by nearly $15 \%$, whereas Republican support grew by more than $17 \%$. Yet when pitted against the strong-con overburdening the system frame (Condition 2), neither partisan group displayed a significant change. ${ }^{24}$

In sum, in all eight instances featuring opposing frames of unequal strength, frames moved opinion significantly in the expected directions (toward the positions supported by the stronger frame), whereas none of the frames in the conditions including opposing frames of equal strength demonstrated significant effects on opinion. Moreover, when the opposing frames pushed opinions in opposite directions, the effects were large, with opinion differences typically in the range of 25 percentage points or more between pro and con frames (i.e., a quarter of the opinion scale). This is strong support for Hypothesis 1, in line with Chong and Druckman (2007) and Druckman (2010). Also, the results are robust among both Democrats and Republicans despite their partisan inclinations in different directions. These results provide a baseline for investigating how the influence of substantive information changes once policy debates also include party cues explicitly indicating where the parties stand on the issue.

\footnotetext{
${ }^{24}$ The weak-weak mix on the DREAM Act comes close to having the pro frame win out among Democrats, although it is not significant at the .1 level, one tailed.
}

Opinion dynamics changed when respondents received party endorsement information; how they change depended substantially on whether polarization is low or high. Figure 2 presents results from the condition where respondents are informed that polarization is low. Recall that, for drilling, Republicans endorsed the pro frame, whereas Democrats endorsed the con frame. For the DREAM Act, Democrats pushed the pro position and Republicans the con. We found mixed support for Hypothesis 3. Specifically, strong arguments, when paired with weak arguments, outperformed party endorsements (Conditions 7 and 8). On drilling, for example, Democratic respondents who received the strong-pro economic argument endorsed by Republicans and the weak-con regulation frame endorsed by the Democrats became more supportive of drilling by $15 \%$. In other words, the party endorsement fell flat and the substance won out. The same was true for Republicans when they received the Democratically endorsed strong-con frame of worker and maritime life (Condition 8)-they followed this by becoming nearly $11 \%$ less supportive, despite also receiving the Republican-endorsed weak-pro frame (technological developments). We saw similar dynamics on the DREAM Act. When arguments varied in strength, substance, not party endorsements, carried the day. This partially contradicted the suggestion from Hypothesis 3 that partisan motivated reasoning will occur throughout both the low- and high-polarizations conditions.

However, Hypothesis 3 was fully supported in the conditions containing equal-strength arguments. Partisans exposed to equally strong or weak frames (Conditions 6 and 9) turned to party endorsements for guidance. On drilling, for example, Republican 


\section{FIGURE 2b. DREAM Act Support, Non-Polarized Party Cues (Democrats Pro, Republicans Con)}

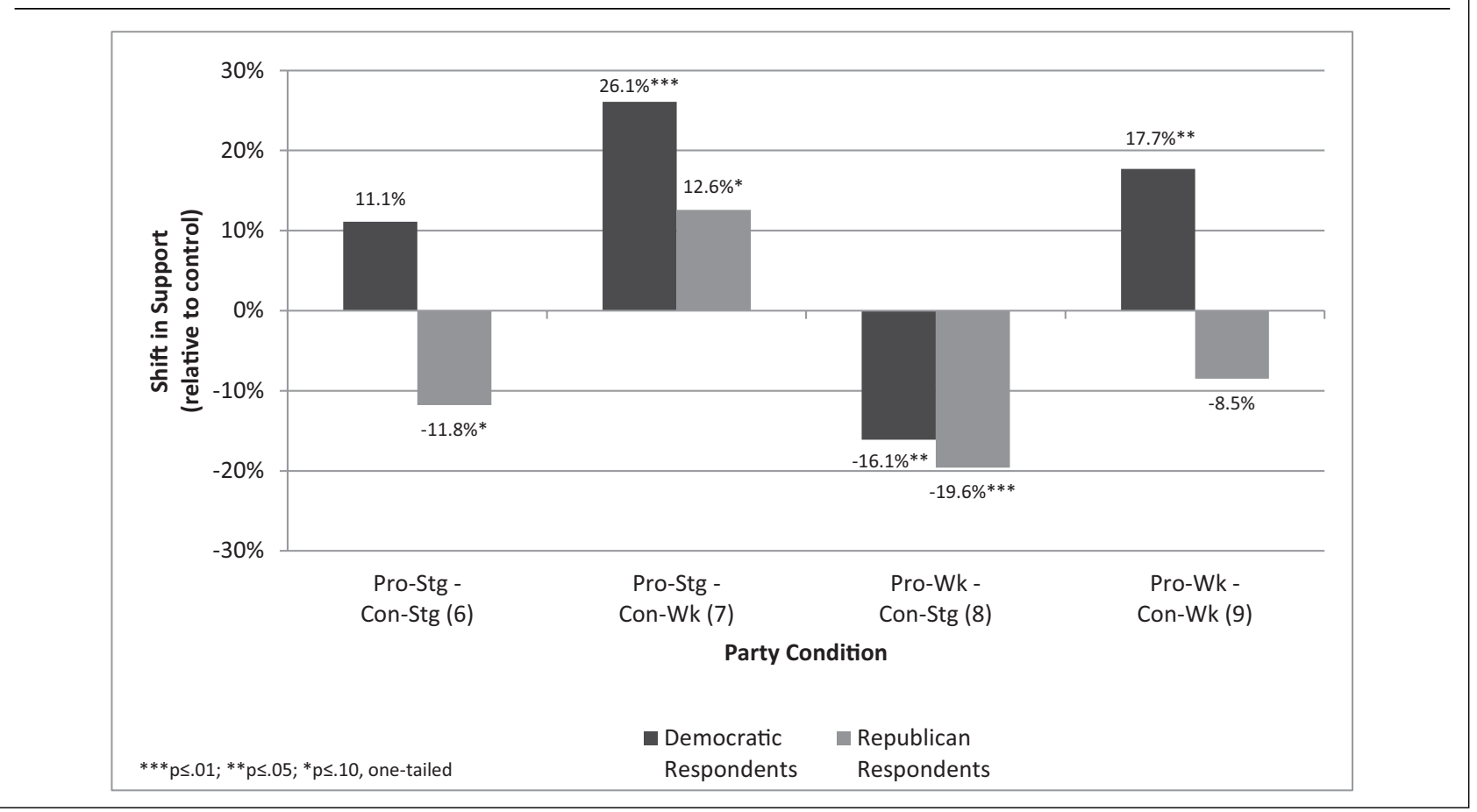

participants encountering the strong-pro economic frame endorsed by Republicans, as well as the strongcon frame worker and maritime life frame from Democrats (Condition 6), followed the Republican endorsement and became more than $10 \%$ more supportive. The same type of dynamic occurred when both drilling frames were weak as well as on analogous DREAM Act conditions-although these movements did not always reach levels of conventional statistical significance.

The results from the non-polarized conditions suggest that cues become important when substantive information is inconclusive as to which policy to support. When arguments/frames are of unequal strength, citizens follow the direction of the stronger argument. Only when the arguments are equally strong do they turn to party cues to find their way. Individuals appear to follow a lexicographical reasoning process where, if the first information considered is not decisive, then a second piece of information is turned to for help (e.g., Payne, Bettman, and Johnson 1993, 26). It is notable, however, that the first piece of relevant information, under conditions of low polarization, is the argument and not the party cue. This echoes Bullock (2011) and Nicholson (2011) in that substance can overwhelm party cues. $^{25}$

This is not the case, however, under conditions of polarization. As Figure 3 demonstrates, partisans ignore

\footnotetext{
${ }^{25}$ Interestingly, in the cases with equal-strength frames, Republicans significantly followed cues three of four times (Conditions 6 and 9 on drilling and Condition 6 on the DREAM Act), whereas Democrats only did so one of four times (Condition 9 on the DREAM Act). This finding suggests stronger Republican cue effects in non-polarized conditions.
}

the substance of the frame and follow their party under conditions of polarization. Consider, once more, the case of drilling. Democrats who received the strong-pro economic frame, endorsed by the Republican Party, and the weak-con regulation frame, endorsed by the Democratic Party (Condition 11), grew nearly 13\% less supportive of drilling for oil. That is, they ignored the stronger substance and responded to party cues. This sharply contrasted with the behavior of similar Democratic partisans facing the same set of arguments in a non-polarized environment. There, Democrats moved toward the stronger frame, despite a Republican endorsement, and became 15\% more supportive (see Condition 7 in Figure 2a). Comparing these two conditions shows a $28 \%$ swing in opinion among Democratic respondents due to polarization. We could go through many other examples evident in Figure 3, but the trend stands across all conditions on both issues: In a polarized partisan environment, partisan motivated reasoning overwhelms substance. These results largely confirm Hypothesis 5; however, they do not fully support it, because the hypothesis predicted greater partisan effects in the polarized than in the non-polarized conditions and we found that partisan effects are sometimes similar across these conditions when the arguments are of equal quality. ${ }^{26}$

\footnotetext{
${ }^{26}$ Technically, confirmation of Hypothesis 5 requires formal comparisons of opinion differences between non-polarized and polarized matched conditions (e.g., 6 and 10). When opinion flipped from pro to con or vice versa between conditions (e.g., Democrats between Conditions 7 and 11 and Republicans between Conditions 8 and 12 on drilling), it is plainly obvious that polarization moved opinions significantly. However, in situations where we expect polarization to further move opinion in a given direction (e.g., Democrats between
} 


\section{FIGURE 3a. Drilling Support, Polarized Party Cues (Republicans Pro, Democrats Con)}

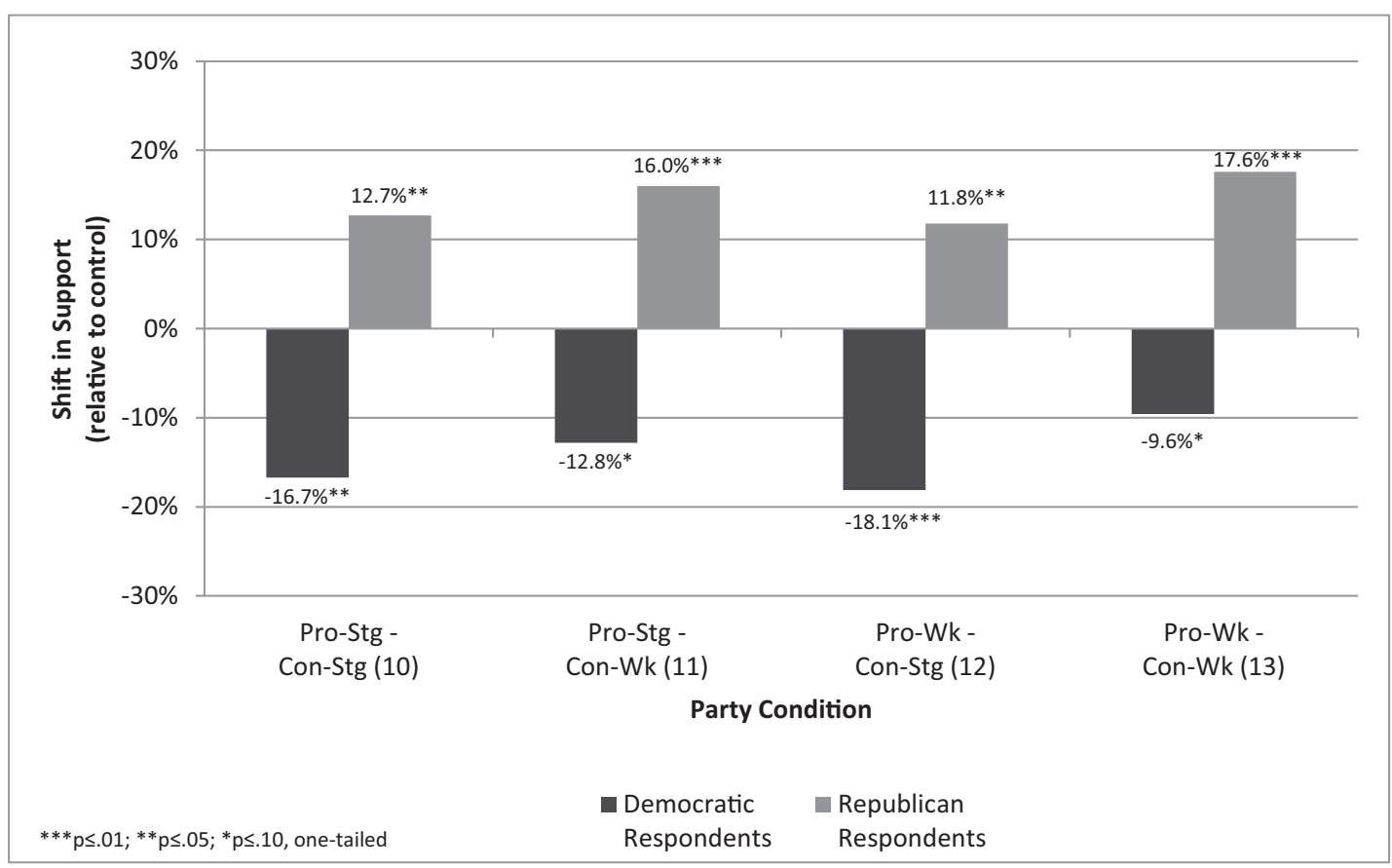

\section{FIGURE 3b. DREAM Act Support, Polarized Party Cues (Democrats Pro, Republicans Con)}

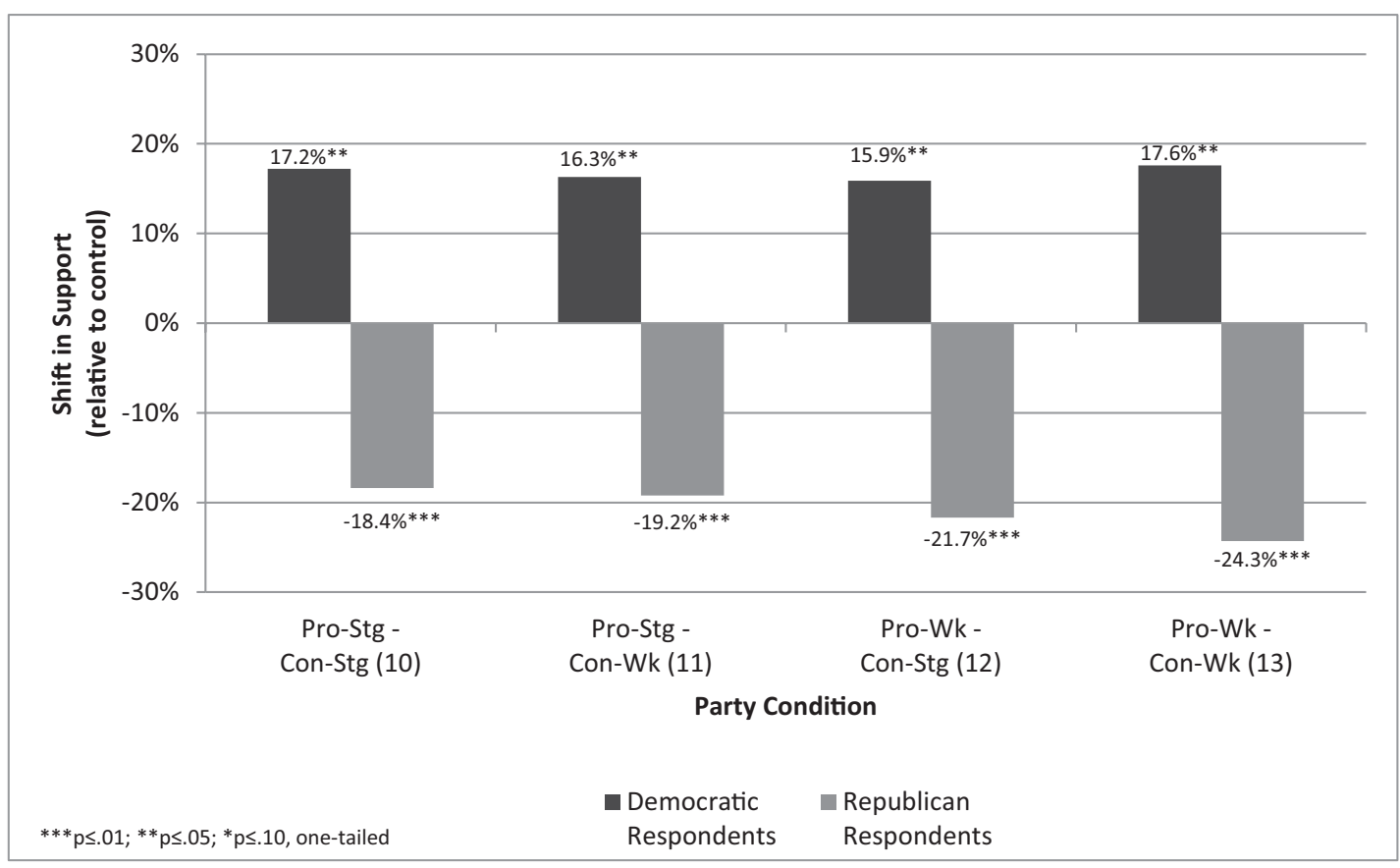

Conditions 8 and 12 or Republicans between Conditions 9 and 13 on drilling), we did not always find opinion differences large enough to be statistically significant. Thus, among Democrats on drilling we found significant differences in opinion between Conditions 6 and 10 ( $p \leq .10$; one-tailed) but not between Conditions 8 and 12 $\overline{(p \leq .13) \text { or } 9 \text { and } 13(p \leq .13) \text {. Likewise, among Republicans, we }}$ found a significant difference in opinion between Conditions 9 and $13(p \leq .10)$ but not between Conditions 6 and 10 or 7 and 11 . Turning to the DREAM Act, we saw significant further movement in opinion among Republicans between Conditions 9 and $13(p<.05)$, but not in the other relevant comparisons. 


\begin{tabular}{|c|c|c|c|c|c|}
\hline Frames (Condition) & Cues & Pro Frame & Con Frame & Difference & $\mathrm{N}$ \\
\hline Pro-Stg - Con-Stg (2) & No Parties & $\begin{array}{l}\quad 4.26 \\
\text { (std. dev. }=1.72 \text { ) }\end{array}$ & $\begin{array}{c}4.37 \\
(1.31)\end{array}$ & $\begin{array}{l}-0.11 \\
(2.69)\end{array}$ & 27 \\
\hline Pro-Stg - Con-Wk (3) & No Parties & $\begin{array}{l}4.68 \\
(1.58)\end{array}$ & $\begin{array}{c}3.39 \\
(1.62)\end{array}$ & $\begin{array}{l}1.29^{* * *} \\
(2.66)\end{array}$ & 38 \\
\hline Pro-Wk - Con-Stg (4) & No Parties & $\begin{array}{l}3.30 \\
(1.23)\end{array}$ & $\begin{array}{l}4.89 \\
(1.48)\end{array}$ & $\begin{array}{l}-1.59 * * * \\
(2.22)\end{array}$ & 27 \\
\hline Pro-Wk - Con-Wk (5) & No Parties & $\begin{array}{l}3.50 \\
(1.45)\end{array}$ & $\begin{array}{l}3.27 \\
(1.76)\end{array}$ & $\begin{array}{l}0.23 \\
(2.34)\end{array}$ & 26 \\
\hline Pro-Stg - Con-Stg (6) & Non-Polarized & $\begin{array}{l}4.15 \\
(1.19)\end{array}$ & $\begin{array}{l}4.46 \\
(1.30)\end{array}$ & $\begin{array}{l}-0.31 \\
(2.19)\end{array}$ & 26 \\
\hline Pro-Stg - Con-Wk (7) & Non-Polarized & $\begin{array}{c}4.44 \\
(1.58)\end{array}$ & $\begin{array}{l}3.74 \\
(1.48)\end{array}$ & $\begin{array}{l}0.70^{*} \\
(2.54)\end{array}$ & 27 \\
\hline Pro-Wk - Con-Stg (8) & Non-Polarized & $\begin{array}{l}3.73 \\
(1.66)\end{array}$ & $\begin{array}{l}4.80 \\
(1.54)\end{array}$ & $\begin{array}{l}-1.07^{* * *} \\
(2.88)\end{array}$ & 30 \\
\hline Pro-Wk - Con-Wk (9) & Non-Polarized & $\begin{array}{l}3.60 \\
(1.12)\end{array}$ & $\begin{array}{l}3.68 \\
(1.18)\end{array}$ & $\begin{array}{l}-0.08 \\
(1.47)\end{array}$ & 25 \\
\hline Pro-Stg - Con-Stg (10) & Polarized & $\begin{array}{l}3.65 \\
(1.50)\end{array}$ & $\begin{array}{l}4.96 \\
(1.30)\end{array}$ & $\begin{array}{l}-1.30^{* * * *} \\
(2.38)\end{array}$ & 23 \\
\hline Pro-Stg - Con-Wk (11) & Polarized & $\begin{array}{l}3.63 \\
(2.01)\end{array}$ & $\begin{array}{c}4.89 \\
(1.45)\end{array}$ & $\begin{array}{l}-1.26^{* *} \\
(3.18)\end{array}$ & 19 \\
\hline Pro-Wk - Con-Stg (12) & Polarized & $\begin{array}{c}3.52 \\
(1.53)\end{array}$ & $\begin{array}{c}4.92 \\
(1.29)\end{array}$ & $\begin{array}{l}-1.40^{* * *} \\
(2.08)\end{array}$ & 25 \\
\hline Pro-Wk - Con-Wk (13) & Polarized & $\begin{array}{l}3.48 \\
(1.48)\end{array}$ & $\begin{array}{c}4.79 \\
(1.57)\end{array}$ & $\begin{array}{l}-1.31^{* * *} \\
(2.16)\end{array}$ & 29 \\
\hline
\end{tabular}

Overall, our results can be summarized as follows:

- When presented with opposing frames of the same strength (with no party endorsements), individuals' opinions are not affected.

- When presented with opposing frames of differing strength (with no party endorsements), individuals' opinions move only in the direction of the strong frame.

- Under conditions of low polarization:

- when presented with opposing frames of different strength (e.g., one strong and one weak), endorsed by different parties, partisans' opinions move only in the direction of the strong frame regardless of the party endorsements. In this case, substance outweighs partisan cues (see Bullock 2011).

- when presented with opposing frames of similar strength (e.g., both strong or both weak), endorsed by different parties, partisans' opinions move only in the direction of the frame endorsed by their party. In this case, party endorsements drive opinions, in the face of arguments that do not differ in strength.

- Under conditions of high polarization, when presented with opposing frames, regardless of strength, partisans' opinions move only in the direction of the frame endorsed by their party. In this case, party endorsements drive opinions, re- gardless of argument strength-that is, even if the other party's argument is stronger.

In sum, partisan endorsements matter in lowpolarization conditions when both parties present arguments of equivalent strength; substance wins out otherwise. Thus, parties do not always rule public opinion. However, substance becomes irrelevant and partisan cues win out when elites polarize. Polarization clearly plays a role in shaping how policy opinion formation works: It stimulates greater motivated reasoning. This finding also suggests that, when elites polarize on a given issue, citizens follow and polarize as well.

\section{Evaluations of Frame Strength}

We next test Hypotheses 2 and 4, which posit that partisan endorsements should affect the evaluations of the frames themselves. This possibility comes directly from the theory of partisan motivated reasoning in which argument source serves as a perceptual screen for evaluating argument quality (e.g., Druckman and Bolsen 2011). We test these hypotheses with our aforementioned measures that asked respondents to assess the "effectiveness" of each frame.

We present the results in Tables 3 and 4: Table 3a for Democrats on drilling, $3 b$ for Republicans on drilling, 4a for Democrats on the DREAM Act, and $4 \mathrm{~b}$ for Republicans on the DREAM Act. Each table reports the average evaluation score of the pro and con frame in each condition (along with the standard deviation). 


\begin{tabular}{|c|c|c|c|c|c|}
\hline Frames (Condition) & Cues & Pro Frame & Con Frame & Difference & $\mathrm{N}$ \\
\hline Pro-Stg - Con-Stg (2) & No Parties & $\begin{array}{c}5.43 \\
(1.16)\end{array}$ & $\begin{array}{c}4.86 \\
(1.68)\end{array}$ & $\begin{array}{l}0.57 \\
(2.25)\end{array}$ & 21 \\
\hline Pro-Stg - Con-Wk (3) & No Parties & $\begin{array}{l}5.29 \\
(1.53)\end{array}$ & $\begin{array}{l}3.12 \\
(1.83)\end{array}$ & $\begin{array}{c}2.18^{* * * *} \\
(2.58)\end{array}$ & 17 \\
\hline Pro-Wk - Con-Stg (4) & No Parties & $\begin{array}{l}3.75 \\
(1.62)\end{array}$ & $\begin{array}{c}4.75 \\
(1.59)\end{array}$ & $\begin{array}{c}-1.00^{* *} \\
(2.78)\end{array}$ & 24 \\
\hline Pro-Wk - Con-Wk (5) & No Parties & $\begin{array}{l}3.75 \\
(1.74)\end{array}$ & $\begin{array}{l}3.40 \\
(1.39)\end{array}$ & $\begin{array}{l}0.35 \\
(2.35)\end{array}$ & 20 \\
\hline Pro-Stg - Con-Stg (6) & Non-Polarized & $\begin{array}{l}5.36 \\
(1.32)\end{array}$ & $\begin{array}{l}3.64 \\
(1.66)\end{array}$ & $\begin{array}{l}1.72^{* * *} \\
(2.46)\end{array}$ & 25 \\
\hline Pro-Stg - Con-Wk (7) & Non-Polarized & $\begin{array}{l}5.23 \\
(1.45)\end{array}$ & $\begin{array}{l}3.00 \\
(1.15)\end{array}$ & $\begin{array}{c}2.23^{* * *} \\
(1.88)\end{array}$ & 22 \\
\hline Pro-Wk - Con-Stg (8) & Non-Polarized & $\begin{array}{l}3.70 \\
(2.20)\end{array}$ & $\begin{array}{c}4.60 \\
(1.76)\end{array}$ & $\begin{array}{c}-0.90^{*} \\
(2.99)\end{array}$ & 20 \\
\hline Pro-Wk - Con-Wk (9) & Non-Polarized & $\begin{array}{c}5.27 \\
(1.28)\end{array}$ & $\begin{array}{l}3.38 \\
(1.36)\end{array}$ & $\begin{array}{l}1.88^{* * *} \\
(2.21)\end{array}$ & 26 \\
\hline Pro-Stg - Con-Stg (10) & Polarized & $\begin{array}{l}5.61 \\
(1.38)\end{array}$ & $\begin{array}{l}3.19 \\
(1.85)\end{array}$ & $\begin{array}{c}2.42^{* * *} \\
(3.03)\end{array}$ & 31 \\
\hline Pro-Stg - Con-Wk (11) & Polarized & $\begin{array}{l}5.67 \\
(1.35)\end{array}$ & $\begin{array}{l}3.07 \\
(1.44)\end{array}$ & $\begin{array}{c}2.60^{* * *} \\
(2.18)\end{array}$ & 30 \\
\hline Pro-Wk - Con-Stg (12) & Polarized & $\begin{array}{l}5.35 \\
(1.66)\end{array}$ & $\begin{array}{l}2.75 \\
(1.52)\end{array}$ & $\begin{array}{c}2.60^{* * * *} \\
(2.66)\end{array}$ & 20 \\
\hline Pro-Wk - Con-Wk (13) & Polarized & $\begin{array}{l}5.10 \\
(1.55)\end{array}$ & $\begin{array}{l}3.19 \\
(1.63)\end{array}$ & $\begin{array}{c}1.90^{* * * *} \\
(2.45)\end{array}$ & 21 \\
\hline
\end{tabular}

\begin{tabular}{|c|c|c|c|c|c|}
\hline Frames (Condition) & Cues & Pro Frame & Con Frame & Difference & $\mathrm{N}$ \\
\hline Pro-Stg - Con-Stg (2) & No Parties & $\begin{array}{c}4.59 \\
(1.62)\end{array}$ & $\begin{array}{c}4.21 \\
(1.68)\end{array}$ & $\begin{array}{l}0.38 \\
(2.87)\end{array}$ & 29 \\
\hline Pro-Stg - Con-Wk (3) & No Parties & $\begin{array}{l}5.03 \\
(1.72)\end{array}$ & $\begin{array}{l}3.35 \\
(1.66)\end{array}$ & $\begin{array}{l}1.68^{* * *} \\
(2.82)\end{array}$ & 31 \\
\hline Pro-Wk - Con-Stg (4) & No Parties & $\begin{array}{l}3.58 \\
(1.73)\end{array}$ & $\begin{array}{l}4.85 \\
(1.30)\end{array}$ & $\begin{array}{c}-1.27^{* * *} \\
(2.49)\end{array}$ & 33 \\
\hline Pro-Wk - Con-Wk (5) & No Parties & $\begin{array}{l}3.76 \\
(1.56)\end{array}$ & $\begin{array}{l}3.84 \\
(1.57)\end{array}$ & $\begin{array}{l}-0.08 \\
(2.52)\end{array}$ & 25 \\
\hline Pro-Stg - Con-Stg (6) & Non-Polarized & $\begin{array}{c}4.74 \\
(1.53)\end{array}$ & $\begin{array}{l}4.19 \\
(1.51)\end{array}$ & $\begin{array}{l}0.55 \\
(2.59)\end{array}$ & 31 \\
\hline Pro-Stg - Con-Wk (7) & Non-Polarized & $\begin{array}{l}5.26 \\
(1.05)\end{array}$ & $\begin{array}{l}2.78 \\
(1.24)\end{array}$ & $\begin{array}{c}2.48^{* * *} \\
(2.11)\end{array}$ & 23 \\
\hline Pro-Wk - Con-Stg (8) & Non-Polarized & $\begin{array}{l}3.67 \\
(1.43)\end{array}$ & $\begin{array}{c}4.50 \\
(1.32)\end{array}$ & $\begin{array}{c}-0.83^{* *} \\
(1.95)\end{array}$ & 24 \\
\hline Pro-Wk - Con-Wk (9) & Non-Polarized & $\begin{array}{c}4.20 \\
(1.47)\end{array}$ & $\begin{array}{l}3.60 \\
(1.63)\end{array}$ & $\begin{array}{l}0.60^{*} \\
(2.39)\end{array}$ & 30 \\
\hline Pro-Stg - Con-Stg (10) & Polarized & $\begin{array}{c}4.75 \\
(1.73)\end{array}$ & $\begin{array}{l}3.71 \\
(1.73)\end{array}$ & $\begin{array}{l}1.04^{* *} \\
(3.06)\end{array}$ & 24 \\
\hline Pro-Stg - Con-Wk (11) & Polarized & $\begin{array}{l}4.96 \\
(1.61)\end{array}$ & $\begin{array}{l}3.08 \\
(1.57)\end{array}$ & $\begin{array}{l}1.88^{* * *} \\
(2.97)\end{array}$ & 26 \\
\hline Pro-Wk - Con-Stg (12) & Polarized & $\begin{array}{c}4.67 \\
(1.27)\end{array}$ & $\begin{array}{l}3.29 \\
(1.71)\end{array}$ & $\begin{array}{l}1.38^{* * *} \\
(2.48)\end{array}$ & 24 \\
\hline Pro-Wk - Con-Wk (13) & Polarized & $\begin{array}{c}4.86 \\
(1.52)\end{array}$ & $\begin{array}{l}3.09 \\
(1.48)\end{array}$ & $\begin{array}{c}1.77^{* * *} \\
(2.05)\end{array}$ & 22 \\
\hline
\end{tabular}




\begin{tabular}{|c|c|c|c|c|c|}
\hline Frames (Condition) & Cues & Pro-Statement & Con-Statement & Difference & $\mathrm{N}$ \\
\hline Pro-Stg - Con-Stg (2) & No Parties & $\begin{array}{c}4.53 \\
(1.42)\end{array}$ & $\begin{array}{c}4.94 \\
(1.78)\end{array}$ & $\begin{array}{l}-0.41 \\
(2.24)\end{array}$ & 17 \\
\hline Pro-Stg - Con-Wk (3) & No Parties & $\begin{array}{l}4.25 \\
(1.80)\end{array}$ & $\begin{array}{l}3.75 \\
(1.39)\end{array}$ & $\begin{array}{l}0.50 \\
(2.30)\end{array}$ & 24 \\
\hline Pro-Wk - Con-Stg (4) & No Parties & $\begin{array}{l}3.69 \\
(2.21)\end{array}$ & $\begin{array}{l}5.31 \\
(1.89)\end{array}$ & $\begin{array}{l}-1.63^{*} \\
(3.69)\end{array}$ & 16 \\
\hline Pro-Wk - Con-Wk (5) & No Parties & $\begin{array}{c}3.52 \\
(1.98)\end{array}$ & $\begin{array}{c}3.68 \\
(1.46)\end{array}$ & $\begin{array}{l}-0.16 \\
(2.43)\end{array}$ & 25 \\
\hline Pro-Stg - Con-Stg (6) & Non-Polarized & $\begin{array}{l}4.15 \\
(1.57)\end{array}$ & $\begin{array}{l}5.15 \\
(1.46)\end{array}$ & $\begin{array}{l}-1.00^{*} \\
(2.73)\end{array}$ & 20 \\
\hline Pro-Stg - Con-Wk (7) & Non-Polarized & $\begin{array}{l}4.33 \\
(1.71)\end{array}$ & $\begin{array}{l}3.67 \\
(1.49)\end{array}$ & $\begin{array}{l}0.67 \\
(2.96)\end{array}$ & 21 \\
\hline Pro-Wk - Con-Stg (8) & Non-Polarized & $\begin{array}{l}3.28 \\
(1.30)\end{array}$ & $\begin{array}{l}4.94 \\
(1.70)\end{array}$ & $\begin{array}{l}-1.66 * * * \\
(2.15)\end{array}$ & 32 \\
\hline Pro-Wk - Con-Wk (9) & Non-Polarized & $\begin{array}{l}3.00 \\
(1.30)\end{array}$ & $\begin{array}{l}3.95 \\
(1.43)\end{array}$ & $\begin{array}{c}-0.95^{* *} \\
(2.11)\end{array}$ & 20 \\
\hline Pro-Stg - Con-Stg (10) & Polarized & $\begin{array}{c}3.36 \\
(1.68)\end{array}$ & $\begin{array}{c}5.18 \\
(1.42)\end{array}$ & $\begin{array}{l}-1.82 * * * \\
(2.67)\end{array}$ & 28 \\
\hline Pro-Stg - Con-Wk (11) & Polarized & $\begin{array}{c}3.00 \\
(1.79)\end{array}$ & $\begin{array}{c}4.96 \\
(1.66)\end{array}$ & $\begin{array}{c}-1.96^{* * *} \\
(3.18)\end{array}$ & 26 \\
\hline Pro-Wk - Con-Stg (12) & Polarized & $\begin{array}{c}2.85 \\
(1.76)\end{array}$ & $\begin{array}{c}4.92 \\
(1.38)\end{array}$ & $\begin{array}{l}-2.08^{* * *} \\
(2.76)\end{array}$ & 26 \\
\hline Pro-Wk - Con-Wk (13) & Polarized & $\begin{array}{c}2.77 \\
(1.69)\end{array}$ & $\begin{array}{c}5.00 \\
(1.63)\end{array}$ & $\begin{array}{c}-2.23^{* * *} \\
(2.72)\end{array}$ & 22 \\
\hline
\end{tabular}

Another key statistic, the difference between evaluations of the pro and con frames, is also listed in each table. Hypotheses 2 and 4 suggest that, as party cues are added, these evaluation differences should become significant, with the argument endorsed by a partisan's own party receiving a more favorable evaluation. A positive significant difference indicates that respondents found the pro frame significantly more effective. A negative significant difference suggests that respondents found the con frame significantly stronger. ${ }^{27}$

As expected, with no party endorsements, partisans of both stripes saw the strong frames as significantly more effective than the weak frames, regardless of whether they are pro or con. (The one exception occurred in Condition 3 for the DREAM Act frames; whereas Democrats rated the pro frame as significantly more effective than the con, the difference between the two for Republican respondents was statistically insignificant from zero.). When the frames are evenly matched, respondents did not see significant differences between them. These findings echo our pretest results and show that both partisan groups agree over which frames are strong and weak. These differences in evaluations of frames are also consistent with the

\footnotetext{
${ }^{27}$ Overall, Democrats found the con frames on drilling and the pro frames on the DREAM Act stronger, whereas Republicans found the opposite frames stronger (i.e., pro frames on drilling and con frames on the DREAM Act). These differences were consistent with partisan values. This is not relevant to our hypotheses, however, because we are concerned with how party cues and polarization change evaluations of these frames.
}

opinion differences found in Figures 1a-b and support an implication of Hypothesis 1.

When we turn to the non-polarized partisan endorsement conditions, the results matched what we found in Figures 2a-b. In short, when facing different strength frames, partisans ignored the endorsements and evaluated the stronger frame as more effective (the only exception is Condition 7 where the DREAM Act difference is not significant among Republicans). These findings again point to the strength of substance over cues in non-polarized conditions. However, we also saw some tendencies for partisan bias in the evaluations of equal-strength frames. Republicans evaluated their party's frame as more effective in the equalstrength non-polarized conditions (6 and 9), indicating motivated reasoning. Similarly, on the DREAM Act, Democrats facing two weak frames (Condition 9) found the frame from their party more persuasive. Overall, however, the substantive content of the frames tended to dominate in their evaluations, even when non-polarized party cues were present, with motivated reasoning only occasionally taking place when the competing frames were equally strong.

We observed very different results in the partisan polarization conditions. We found that partisans always evaluated the frames endorsed by their party as significantly stronger, regardless of the policy issue. Thus, polarization seems to spark motivated reasoning, and people clearly evaluate frames differently in the presence of polarization. On the drilling issue, this was most apparent for Democrats by comparing Conditions 3, 
7, and 11-all conditions that included a strong-pro frame and a weak-con frame. In the no-party cue and non-polarized cue conditions, the Democratic participants saw the pro frame as significantly stronger. Yet, this flipped completely in the polarized condition (11). For Republicans, we saw the exact same dynamic in Conditions 4, 8, and 12. In the two former conditions, Republicans always evaluated the con frame as significantly stronger (even though their party endorses the opposite side of the issue), but when the parties were polarized (12), this switched and they perceived the pro frame as significantly stronger. This means that motivated reasoning affected both the pro and con frames. Again, similar dynamics occurred on the DREAM Act issue. These results strongly supported Hypothesis 2 and partially supported Hypothesis 4. We observed only partial support for Hypothesis 4 because some motivated reasoning took place in the non-polarized conditions when the arguments were of equal strength (i.e., there was not always statistically significantly greater motivated reasoning in the polarized than non-polarized conditions) ${ }^{28}$

In sum, these frame evaluation dynamics demonstrated that partisan polarization influences both the extent to which citizens rely on substantive information and party cues when forming policy opinions and how citizens process substantive arguments. Participants from both parties evaluated the stronger frame as more persuasive in conditions without a party endorsement, and they also did so, largely, in a low-polarization environment when the strong frame is matched with a weak frame. Partisan polarization altered the argument evaluation process, however, with strong frames rated as ineffective in polarized conditions if they did not receive an endorsement from the individual's own party. In these same polarized conditions, half-hearted evaluations of weak frames turned into enthusiastic evaluations if the frame received an endorsement by the individual's party. These findings further empha-

\footnotetext{
28 To see if the differences in frame evaluations were different under polarization than non-polarization, we compared the significance of frame evaluations across analogous conditions (e.g., in non-polarized versus polarized cases). On the drilling issue, among Democrats, the expected differences were statistically significant (at $p \leq .10$ or lower, one-tailed tests). Thus, in all conditions, when expected, the frame sponsored by the Democrats was evaluated more favorably (relative to the opposite frame) in the polarized conditions than in the nonpolarized conditions. The only case where, as expected, there was not a difference was between Conditions 8 and 12 because the strong frame is consistent with the party endorsement (so regardless of the standard of evaluation, the Democratic frame should be seen as the strongest in both conditions). Among Republicans, however, there were not the expected differences between Conditions 6 and 10 and 9 and 13, largely because Republicans already in the non-polarized conditions, as noted, showed signs of motivated reasoning. Turning to the DREAM Act issue, we found the expected differences significant for Democrats, except between Conditions 6 and 10 where the difference in assessments of frames was in the expected direction but was not large enough to reach statistical significance. Among Republicans, tests of significance confirmed the expected differences, except between Conditions 6 and 10 where Republicans, again, showed some motivated reasoning in the non-polarized conditions. We again found the expected nonsignificant comparisons between Conditions 7 and 11 for Democrats and 8 and 12 for Republicans (when the frames and cues agreed with one another).
}

size that partisan polarization is a crucial condition for how citizens respond to competing sides in policy debates. It is also evidence of partisan motivated reasoning whereby a salient partisan identity colors argument evaluation. Party endorsements, particularly under conditions of polarization, do not appear to simply serve as cues people follow. Instead, cues seem to shape how the public views arguments put forth by different sides.

\section{Opinion Importance}

Our final hypothesis (6) posits that opinion importance should grow as a partisan sponsor is added and, particularly, when the parties are polarized. This is a somewhat ironic prediction insofar as people are gaining confidence in opinions that, in some sense, are less based on the substance of the argument. We tested this hypothesis with our item that asked individuals to rate, on a 7-point scale, how much importance they attached to their attitude on each issue.

To test this hypothesis, we used the control group as a baseline and expected that adding partisan sponsors, particularly under conditions of polarization, should result in an increase in attitude importance. We present the percentage change relative to the control group for each condition and each partisan group in Table 5 . We present the means and standard deviations in Appendix B (Tables B.3 and B.4). The results accentuate the dramatic effect that partisan polarization can have. Without a polarized environment, we saw little change in attitude importance-the only significant changes came from Republicans in equal-strength conditions (6 and 9 ) on the drilling issue and marginally by Democrats in Condition 8 on the DREAM Act. Yet in every polarized condition, and for both issues, individuals became dramatically more confident in their opinions (by $12 \%$ to $18 \%$ ). Thus, Hypothesis 6 is supported because the polarized conditions have a significantly greater impact on attitude importance than the nonpolarized conditions in nearly every case (although we did expect more changes in the non-polarized conditions than were observed). ${ }^{29}$

In short, not only does a polarized environment increase partisan motived reasoning-and decrease reliance on substance-but it also causes people to view their opinions as more important. Attitude importance, in turn, has been shown to affect a variety of behaviors such as willingness to persuade others or otherwise take action on behalf of an issue (Visser et al. 2006). In the long term, overconfidence may speak to the stability of political parties in general (Johnson and Fowler 2011), which may be of concern: Polarized parties lead to more confidence in opinions; that is, people consider

\footnotetext{
${ }^{29}$ As noted with regard to other hypotheses, confirmation of Hypothesis 6 required comparing differences between non-polarized and polarized conditions. By merging the four polarized conditions and comparing them with the four non-polarized conditions, we found that opinions on both policy issues were significantly more important under conditions of polarization than non-polarization, among both Democrats and Republicans.
} 


\section{TABLE 5a. Shift in Attitude Importance of Drilling Opinions (Relative to Control Group)}

\begin{tabular}{llcc}
\hline Frames (Condition) & \multicolumn{1}{c}{ Cues } & Democrats & Republicans \\
\hline Pro-Stg - Con-Stg (2) & No Parties & $-2.3 \%$ & $-4.5 \%$ \\
Pro-Stg - Con-Wk (3) & No Parties & $3.2 \%$ & $7.7 \%$ \\
Pro-Wk - Con-Stg (4) & No Parties & $-1.0 \%$ & $0.7 \%$ \\
Pro-Wk - Con-Wk (5) & No Parties & $-2.4 \%$ & $-6.3 \%$ \\
Pro-Stg - Con-Stg (6) & Non-Polarized & $-0.5 \%$ & $14.6 \% \%^{* * *}$ \\
Pro-Stg - Con-Wk (7) & Non-Polarized & $3.9 \%$ & $-4.4 \%$ \\
Pro-Wk - Con-Stg (8) & Non-Polarized & $5.3 \%$ & $7.1 \%$ \\
Pro-Wk - Con-Wk (9) & Non-Polarized & $2.1 \%$ & $8.8 \% \%^{* *}$ \\
Pro-Stg - Con-Stg (10) & Polarized & $11.6 \% \%^{* * *}$ & $15.1 \% \%^{* * *}$ \\
Pro-Stg - Con-Wk (11) & Polarized & $12.9 \% \%^{* * *}$ & $16.3 \% \%^{* * *}$ \\
Pro-Wk - Con-Stg (12) & Polarized & $10.8 \% \%^{* *}$ & $13.8 \% \%^{* * *}$ \\
Pro-Wk - Con-Wk (13) & Polarized & $12.4 \% * *$ & $13.8 \% \%^{* * *}$ \\
\hline *** $p \leq .01 ;{ }^{* *} p \leq .05 ;{ }^{*} p \leq .10$ for one-tailed tests (relative to the control group). & & \\
\hline
\end{tabular}

\section{TABLE 5b. Shift in Attitude Importance of DREAM Act Opinions (Relative to Control Group)}

\begin{tabular}{llcc}
\hline Frames (Condition) & \multicolumn{1}{c}{ Cues } & Democrats & Republicans \\
\hline Pro-Stg - Con-Stg (2) & No Parties & $2.0 \%$ & $1.6 \%$ \\
Pro-Stg - Con-Wk (3) & No Parties & $0.9 \%$ & $-4.2 \%$ \\
Pro-Wk - Con-Stg (4) & No Parties & $-4.1 \%$ & $7.6 \%$ \\
Pro-Wk - Con-Wk (5) & No Parties & $6.8 \%$ & $7.6 \%$ \\
Pro-Stg - Con-Stg (6) & Non-Polarized & $7.4 \%$ & $5.6 \%$ \\
Pro-Stg - Con-Wk (7) & Non-Polarized & $4.3 \%$ & $3.2 \%$ \\
Pro-Wk - Con-Stg (8) & Non-Polarized & $-9.0 \% *$ & $7.1 \%$ \\
Pro-Wk - Con-Wk (9) & Non-Polarized & $8.1 \%$ & $1.4 \%$ \\
Pro-Stg - Con-Stg (10) & Polarized & $16.0 \% * *$ & $18.1 \% * * *$ \\
Pro-Stg - Con-Wk (11) & Polarized & $12.3 \% * *$ & $17.1 \% \%^{* *}$ \\
Pro-Wk - Con-Stg (12) & Polarized & $12.6 \% * *$ & $17.1 \% * * *$ \\
Pro-Wk - Con-Wk (13) & Polarized & $9.8 \% *$ & $12.4 \% *$ \\
\hline${ }^{* * *} p \leq .01 ;{ }^{* *} p \leq .05 ;{ }^{*} p \leq .10$ for one-tailed tests (relative to the control group). & & \\
\hline
\end{tabular}

them more important-even though these opinions are less substantively grounded (i.e., confidence is one dimension of attitude importance). This is a neglected consequence of partisan polarization.

\section{CONCLUSION}

We find that, in the absence of party endorsements, the strength of the arguments/frames in play drives opinions (e.g., Chong and Druckman 2007). Moreover, frame strength continues to play this role in nonpolarized conditions, overwhelming the influence of party cues on attitudes (e.g., Bullock 2011; Nicholson 2011). Party cues only begin to exert influence in nonpolarized competitive environments when the parties offer equally strong arguments and individuals then turn to something other than substance for guidance. This suggests a lexicographical psychology in which individuals turn to a primary piece of information and follow it when it is definitive. If it lacks clarity, however, they turn to secondary information, in this case party endorsements.

A polarized environment causes this order of priority to apparently shift, such that a strengthened partisan identity causes party endorsements to carry the day. Unlike the no-cue and non-polarized conditions, partisans in a polarized environment follow their party regardless of the type or strength of the argument the party makes (also see Slothuus and de Vreese 2010). Moreover, when individuals engage in strong partisan motivated reasoning, they develop increased confidence in their opinions. This means they are less likely to consider alternative positions and more likely to take action based on their opinion (e.g., attempt to persuade others; Visser et al. 2006). In short, elite polarization fundamentally changes the manner in which citizens make decisions.

Our results raise a number of normative questions. Previous work on motivated reasoning has emphasized the negative implications it holds for the quality of public preferences. Following this line of thought, our 
findings of increased motivated reasoning in polarized environments indicate lower quality opinions in these conditions. For example, Lavine, Johnston, and Steenbergen (2012) state that motivated reasoning "raises deeply troubling questions about political representation... how can an electorate possibly reward or punish an incumbent party if it holds grossly distorted views of political conditions? And how can it elect leaders who will pursue desired policy reform in the face of widespread misperception about where leaders stand, what the policy status quo is, and what the central elements and likely consequences of proposed reform are?" (chapter 5: 6; also see Jerit 2009). Moreover, partisan motived reasoning, as is made clear by Chong and Druckman (2010), Druckman and Leeper (2012a), and Druckman et al. (2012), can lead to dogmatic adherence to a prior opinion to the point of extreme inflexibility and intolerance. Viewed from this perspective, our study provides another example of the normatively undesirable outcomes of motivated reasoning, this time with polarization ultimately to blame for triggering motivated reasoning. In polarized conditions citizens turn to partisan biases and ignore arguments that they otherwise consider to be "strong."

We are sympathetic to this perspective insofar as motivated reasoning leads citizens to ignore substantive information. However, this sympathy does not preclude an acknowledgment of alternative interpretations of the relationship between polarization and opinion quality. In particular the normative case for lower opinion quality in conditions of polarization requires assuming that "stronger" arguments are more normatively desirable. Exactly whether "stronger" arguments are in fact normatively better arguments remains unclear. Indeed, the extant work that attempts to unpack what makes citizens believe arguments are stronger or weaker suggests inherent biases in these perceptions (e.g., what is strong may not be what one would find normatively desirable; for discussion, see Druckman 2011).

Concluding that polarization leads to low-quality opinions would stand in contrast to previous work on the topic. Levendusky (2010), although clearly acknowledging some downsides of polarization, paints a more optimistic picture of how polarization affects opinion quality. The difference stems from Levendusky's focus on how polarization facilitates the creation of ideological coherent opinions, the use of cues, and the likelihood of "voting correctly" (operationalized by low-information voters emulating the behavior of high-information voters).

Finally, previous work has also championed the positive normative results of cue taking (e.g., White and Ypi 2011). Indeed, Nicholson and Heit (2012) offer compelling evidence that citizens clearly understand what the parties represent, and as a result, relying on party cues can indicate informed decision making. This claim coheres with a long line of argument on how cues can make for quality decisions (e.g., Lupia 1994; Nicholson 2012; Sniderman, Brody, and Tetlock 1991). This work suggests that an increased role for cues in opinion formation, as observed in the polarized condi- tions of our study, is not inherently problematic, even if this increased cue taking comes at the expense of substantive information.

These differences-in concluding polarization leads to "better" or "worse" opinions-accentuate the larger question: What exactly do we want "quality" opinions to be? Despite more than a century of grappling with what makes for a "good" public opinion, scholars and theorists continue to advance widely different and contradictory standards (for a full assessment, see Druckman 2011; 2012). This divergence has far more than pedantic implications-if political scientists hope to play a role in promoting civic competence and coherent voting behavior, there needs to be greater discussion on what it means to be competent. This requires increased conversations between empirical scholars and normative theorists.

In addition to discussions of opinion quality, our results also have implications for research on the role of political parties in a democracy. To the extent that one finds our results troubling-in that intense party competition degenerates opinion quality-they then call into question or at least stimulate discussion about the 60-year-old plea for strong parties in the United States (APSA 1950; for the latest state-of-the-art work on political parties, see Sniderman and Stiglitz 2012). Although strong, clearly defined parties have benefits, they also may come with previously neglected costs.

Regarding whether or not polarization is occurring at the mass level, our results suggest that the answer may be more complicated than commonly recognized. In short, we suspect citizen polarization occurs issue by issue-it will depend both on elite polarization on a given issue and the information-search patterns of citizens themselves (see Druckman et al. 2012). How these factors aggregate into overall ideological citizen polarization will depend on the weights given to distinct issues (also see Ura and Ellis 2012). ${ }^{30}$

A final comment concerns the general implications for democratic competition. Competition is a defining element of even the most minimalist conceptions of democracy. Yet when it comes to the impact of competition on public opinion formation, the opinion dynamics involved can be problematic. Chong and Druckman (2010) suggest that competition over time prioritizes the argument that comes last, and thus the ordering of arguments means competitors are not on equal footing. Druckman et al. (2012) show that the

\footnotetext{
${ }^{30}$ We view our work as setting an agenda for more research into how elite polarization affects not only whether citizens themselves polarize but also how polarization affects how they arrive at their policy opinions. There are a number of alternative situations worth exploring. For example, Nicholson (2012) finds that it is out-party sponsorship and not in-party sponsorship that drives opinion formation-an idea we cannot explicitly test because our partisan conditions include cues from both parties. Nicholson also draws a sharp distinction between individual partisan politicians (e.g., presidential candidates) and parties themselves-another difference we cannot test given our focus on parties in general. Finally, Nicholson (2011) suggests that variations in the messages (e.g., including explicit references to other groups) can temper source effects, and Mackie, Worth, and Asuncion (1990) suggest that effects also may depend on the relevance of the issue at hand
} 
ordering depends on whether people seek out information; when they do, the argument that comes first is more powerful. Regardless, because politics takes place over time and hence so does competition, one should not presume that competition works perfectly in how it shapes opinions. Our evidence adds yet another consequence by suggesting that intense competition can alter how decisions are made. Clearly, the timing, nature, and intensity of competition affect preference formation, and future work that fails to incorporate these political realities will also fail to come to grips with the dynamics of opinion formation.

\section{APPENDIX A}

\section{Experimental Stimulus Material}

A.1. Experimental Stimulus on Drilling Issue.

[All:] There has been a lot of recent discussion about whether to allow drilling for oil and gas off the Atlantic Coast and in the eastern Gulf of Mexico.

[Non-Polarized Party Cues:] Republicans in Congress tend to favor drilling and Democrats in Congress tend to oppose drilling. However, the partisan divide is not stark as the parties are not too far apart. Also, while Republicans tend to be in favor and Democrats opposed, members of each party can be found on both sides of the issue.

[Polarized Party Cues:] Republicans in Congress tend to favor drilling and Democrats in Congress tend to oppose drilling. Moreover, the partisan divide is stark as the parties are far apart. Also, not only do Republicans tend to be in favor and Democrats opposed, but most members of each party are on the same side as the rest of their party.

[Strong-Pro Frame:] The main argument for those in favor of drilling is that drilling increases our oil supply, which leads to lower gas prices. It also generates employment opportunities and development.

[Weak-Pro Frame:] The main argument for those in favor of drilling is that drilling encourages the development of new technologies, such as sound mitigation techniques. These technologies sometimes have general applications.

[Strong-Con Frame:] The main argument for those opposed to drilling is that workers are required to learn new skills in order to protect themselves against the dangers of drilling. Marine life also must adapt to survive in the face of site construction and drilling.
[Weak-Con Frame:] The main argument for those opposed to drilling is that government regulators oversee the drilling. These regulatory agencies recently have expressed being overwhelmed by oversight tasks.

A.2. Experimental Stimulus on DREAM Act Issue. [All:] Since 2001, lawmakers have debated a new immigration law called the Development, Relief, and Education for Alien Minors Act (also called the DREAM Act). The law would allow undocumented immigrants to gain citizenship if they:

$$
\begin{aligned}
& \text { entered the United States before the age of 16, } \\
& \text { maintained good moral character (e.g., no criminal } \\
& \text { record), } \\
& \text { earned a High School Diploma, and } \\
& \text { completed two years of college OR two years of } \\
& \text { military service. }
\end{aligned}
$$

[Non-Polarized Party Cues:] Democrats in Congress tend to favor the DREAM Act and Republicans in Congress tend to oppose the DREAM Act. However, the partisan divide is not stark as the parties are not too far apart. Also, while Democrats tend to be in favor and Republicans opposed, members of each party can be found on both sides of the issue.

[Polarized Party Cues:] Democrats in Congress tend to favor the DREAM Act and Republicans in Congress tend to oppose the DREAM Act. Moreover, the partisan divide is stark as the parties are far apart. Also, not only do Democrats tend to be in favor and Republicans opposed, but most members of each party are on the same side as the rest of their party.

[Strong-Pro Frame:] The main argument for those in favor of the DREAM Act is that it would provide young people with opportunities. They could go on to contribute as doctors, nurses, teachers, soldiers, and police officers.

[Weak-Pro Frame:] The main argument for those in favor of the DREAM Act is that it has been a topic in several public opinion polls. These polls suggest support from many segments of the American population.

[Strong-Con Frame:] The main argument for those opposed to the DREAM Act is that it encourages illegal immigration due to the expectation of benefits for children of immigrants. This could over-burden the system, leaving many vulnerable individuals.

[Weak-Con Frame:] The main argument for those opposed to the DREAM Act is that it is not well-designed-it could be better. It was driven too much by political concerns in an effort to bring up a controversial issue. 


\section{APPENDIX B}

\section{Condition Means}

\section{TABLE B.1. Drilling Support by Experimental Condition}

\begin{tabular}{llll}
\hline Experimental Condition & \multicolumn{1}{c}{ All } & Democrats & Republicans \\
\hline (1) Control group & $\begin{array}{c}\text { 4.34 (std. dev. }=1.55, \\
\mathrm{~N}=47)\end{array}$ & $3.61(1.37,23)$ & $5.04(1.40,24)$ \\
& $4.44(1.56,48)$ & $3.74(1.58,27)$ & $5.33(0.97,21)$ \\
(2) Pro-Strong - Con-Strong No Parties & $5.09(1.65,55)$ & $4.74(1.80,38)$ & $5.88(0.86,17)$ \\
(3) Pro-Strong - Con-Weak No Parties & $3.65(1.53,51)$ & $2.96(1.40,27)$ & $4.42(1.32,24)$ \\
(4) Pro-Weak - Con-Strong No Parties & $4.50(1.75,46)$ & $3.92(1.79,26)$ & $5.25(1.41,20)$ \\
(5) Pro-Weak - Con-Weak No Parties & $4.45(1.86,51)$ & $3.27(1.66,26)$ & $5.68(1.11,25)$ \\
(6) Pro-Strong - Con-Strong Non-Polarized Parties & $4.52(1.95,27)$ & $5.91(1.23,22)$ \\
(7) Pro-Strong - Con-Weak Non-Polarized Parties & $5.14(1.79,49)$ & $3.00(1.58,30)$ & $4.40(1.70,20)$ \\
(8) Pro-Weak - Con-Strong Non-Polarized Parties & $3.56(1.75,50)$ & $3.44(1.36,25)$ & $5.65(1.29,26)$ \\
(9) Pro-Weak - Con-Weak Non-Polarized Parties & $4.57(1.72,51)$ & $2.61(1.73,23)$ & $5.81(1.30,31)$ \\
(10) Pro-Strong - Con-Strong Polarized Parties & $4.44(2.18,54)$ & $2.84(1.74,19)$ & $6.00(1.31,30)$ \\
(11) Pro-Strong - Con-Weak Polarized Parties & $4.78(2.14,49)$ & $2.52(1.36,25)$ & $5.75(1.48,20)$ \\
(12) Pro-Weak - Con-Strong Polarized Parties & $3.96(2.14,45)$ & $3.03(1.27,29)$ & $6.10(1.00,21)$ \\
(13) Pro-Weak - Con-Weak Polarized Parties & $4.32(1.91,50)$ & $3.46(1.72,345)$ & $5.50(1.37,301)$ \\
Overall & $4.41(1.86,646)$ &
\end{tabular}

Note: Entries are mean policy support on a 1-7 scale, with standard deviations and number of cases in parentheses. Democratic party position is con; Republican party position is pro.

TABLE B.2. DREAM Act Support by Experimental Condition

\begin{tabular}{llll}
\hline Experimental Condition & \multicolumn{1}{c}{ All } & Democrats & Republicans \\
\hline (1) Control group & $\begin{array}{l}3.55(\text { std. dev. }=2.11, \\
N=47)\end{array}$ & $4.17(2.12,23)$ & $2.96(1.97,24)$ \\
& $3.59(2.27,46)$ & $3.97(2.37,29)$ & $2.94(1.98,17)$ \\
(2) Pro-Strong - Con-Strong No Parties & $4.60(1.91,55)$ & $5.06(1.88,31)$ & $4.00(1.82,24)$ \\
(3) Pro-Strong - Con-Weak No Parties & $2.82(1.76,49)$ & $3.33(1.71,33)$ & $1.75(1.39,16)$ \\
(4) Pro-Weak - Con-Strong No Parties & $3.76(2.24,50)$ & $4.84(1.91,25)$ & $2.68(2.04,25)$ \\
(5) Pro-Weak - Con-Weak No Parties & $3.82(2.20,51)$ & $4.84(1.95,31)$ & $2.25(1.55,20)$ \\
(6) Pro-Strong - Con-Strong Non-Polarized Parties & $5.74(1.21,23)$ & $3.71(1.90,21)$ \\
(7) Pro-Strong - Con-Weak Non-Polarized Parties & $4.77(1.87,44)$ & $3.21(1.82,24)$ & $1.78(0.91,32)$ \\
(8) Pro-Weak - Con-Strong Non-Polarized Parties & $2.39(1.53,56)$ & $5.23(1.83,30)$ & $2.45(1.93,20)$ \\
(9) Pro-Weak - Con-Weak Non-Polarized Parties & $4.12(2.31,50)$ & $5.21(2.06,24)$ & $1.86(0.97,28)$ \\
(10) Pro-Strong - Con-Strong Polarized Parties & $3.40(2.29,52)$ & $5.15(1.87,26)$ & $1.81(1.10,26)$ \\
(11) Pro-Strong - Con-Weak Polarized Parties & $3.48(2.27,52)$ & $5.13(1.80,24)$ & $1.65(0.98,26)$ \\
(12) Pro-Weak - Con-Strong Polarized Parties & $3.32(2.25,50)$ & $5.23(1.51,22)$ & $1.50(0.80,22)$ \\
(13) Pro-Weak - Con-Weak Polarized Parties & $3.36(2.23,44)$ & $4.67(1.99,345)$ & $2.38(1.68,301)$ \\
Overall & $3.60(2.18,646)$ & &
\end{tabular}

Note: Entries are mean policy support on a 1-7 scale, with standard deviations and number of cases in parentheses. Democratic party position is pro; Republican party position is con. 


\begin{tabular}{llll}
\multicolumn{4}{l}{ TABLE B.3. Shift in Attitude Importance of Drilling Opinions by Experimental Condition } \\
\hline Experimental Condition & \multicolumn{1}{c}{ All } & \multicolumn{1}{c|}{ Democrats } & Republicans \\
\hline (1) Control group & \multicolumn{1}{c}{$5.02(\mathrm{std} . \mathrm{dev} .=1.05}$, & $4.91(1.04,23)$ & $5.13(1.08,24)$ \\
& $\mathrm{N}=47)$ & & \\
(2) Pro-Strong - Con-Strong No Parties & $4.80(1.53,48)$ & $4.78(1.63,27)$ & $4.86(1.42,21)$ \\
(3) Pro-Strong - Con-Weak No Parties & $5.25(1.31,55)$ & $5.11(1.33,38)$ & $5.59(1.23,17)$ \\
(4) Pro-Weak - Con-Strong No Parties & $5.00(1.28,51)$ & $4.85(1.41,27)$ & $5.17(1.13,24)$ \\
(5) Pro-Weak - Con-Weak No Parties & $4.76(1.25,46)$ & $4.77(1.24,26)$ & $4.75(1.29,20)$ \\
(6) Pro-Strong - Con-Strong Non-Polarized Parties & $5.43(1.25,51)$ & $4.88(1.40,26)$ & $6.00(0.76,25)$ \\
(7) Pro-Strong - Con-Weak Non-Polarized Parties & $5.02(1.44,49)$ & $5.15(1.29,27)$ & $4.86(1.61,22)$ \\
(8) Pro-Weak - Con-Strong Non-Polarized Parties & $5.36(1.60,50)$ & $5.23(1.65,30)$ & $5.55(1.54,20)$ \\
(9) Pro-Weak - Con-Weak Non-Polarized Parties & $5.35(1.04,51)$ & $5.04(0.98,25)$ & $5.65(1.02,26)$ \\
(10) Pro-Strong - Con-Strong Polarized Parties & $5.85(1.11,54)$ & $5.61(1.27,23)$ & $6.03(0.95,31)$ \\
(11) Pro-Strong - Con-Weak Polarized Parties & $5.94(1.03,49)$ & $5.68(1.00,19)$ & $6.10(1.03,30)$ \\
(12) Pro-Weak - Con-Strong Polarized Parties & $5.73(1.05,45)$ & $5.56(1.12,25)$ & $5.95(0.94,20)$ \\
(13) Pro-Weak - Con-Weak Polarized Parties & $5.78(.02,50)$ & $5.66(1.14,29)$ & $5.95(0.80,21)$ \\
Overall & $5.34(1.29,646)$ & $5.16(1.32,345)$ & $5.54(1.22,301)$ \\
\hline
\end{tabular}

\begin{tabular}{|lccc|}
\hline \multicolumn{4}{l}{$\begin{array}{l}\text { TABLE B.4. Shift in Attitude Importance of DREAM Act Opinions by Experimental } \\
\text { Condition }\end{array}$} \\
\hline Experimental Condition & All & Democrats & Republicans \\
\hline (1) Control group & $4.79(1.83,47)$ & $4.91(2.00,23)$ & $4.67(1.69,24)$ \\
(2) Pro-Strong - Con-Strong No Parties & $4.93(1.83,46)$ & $5.03(1.72,29)$ & $4.76(2.05,17)$ \\
(3) Pro-Strong - Con-Weak No Parties & $4.73(1.68,55)$ & $4.97(1.40,31)$ & $4.42(1.98,24)$ \\
(4) Pro-Weak - Con-Strong No Parties & $4.82(1.35,49)$ & $4.67(1.47,33)$ & $5.13(1.02,16)$ \\
(5) Pro-Weak - Con-Weak No Parties & $5.22(1.15,50)$ & $5.32(0.90,25)$ & $5.12(1.36,25)$ \\
(6) Pro-Strong - Con-Strong Non-Polarized Parties & $5.22(1.33,51)$ & $5.35(1.31,31)$ & $5.00(1.38,20)$ \\
(7) Pro-Strong - Con-Weak Non-Polarized Parties & $5.02(1.32,44)$ & $5.17(1.23,23)$ & $4.86(1.42,21)$ \\
(8) Pro-Weak - Con-Strong Non-Polarized Parties & $4.79(1.57,56)$ & $4.38(1.69,24)$ & $5.09(1.42,32)$ \\
(9) Pro-Weak - Con-Weak Non-Polarized Parties & $5.14(1.20,50)$ & $5.40(1.10,30)$ & $4.75(1.25,20)$ \\
(10) Pro-Strong - Con-Strong Polarized Parties & $5.81(1.07,52)$ & $5.88(1.23,24)$ & $5.75(0.93,28)$ \\
(11) Pro-Strong - Con-Weak Polarized Parties & $5.67(1.31,52)$ & $5.65(1.35,26)$ & $5.69(1.29,26)$ \\
(12) Pro-Weak - Con-Strong Polarized Parties & $5.68(1.25,50)$ & $5.67(1.27,24)$ & $5.69(1.26,26)$ \\
(13) Pro-Weak - Con-Weak Polarized Parties & $5.45(1.32,44)$ & $5.50(1.30,22)$ & $5.41(1.37,22)$ \\
Overall & $5.17(1.45,646)$ & $5.21(1.44,345)$ & $5.13(1.47,301)$ \\
\hline
\end{tabular}

\section{REFERENCES}

Aarøe, Lene. 2011. "Investigating Frame Strength." Political Communication 28 (April): 207-26.

American Political Science Association. Committee on Political Parties. 1950. "Toward a More Responsible Two-party System."

Arceneaux, Kevin. 2008. "Can Partisan Cues Diminish Democratic Accountability?" Political Behavior 30 (June): 139-60.

Bartels, Larry 2002. "Beyond the Running Tally." Political Behavior 24 (June): 117-50.

Boiney, Lindsley G., Jane Kennedy, and Pete Nye. 1997. "Instrumental Bias in Motivated Reasoning: More When More is Needed." Organizational Behavior and Human Decision Processes 72 (October): 1-24.

Bolsen, Toby, and Fay Lomax Cook. 2008. "Public Opinion on Energy Policy, 1974-2006.” Public Opinion Quarterly 72 (2): 364-88.

Boudreau, Cheryl. N.d. "Gresham's Law of Cue-Taking." Political Communication. Forthcoming.

Brader, Ted. 2006. Campaigning for Hearts and Minds. Chicago: University of Chicago Press.

Brewer, Paul R. 2001. "Value Words and Lizard Brains." Political Psychology 22 (March): 45-64.

Bullock, John G. 2011. "Elite Influence on Public Opinion in an Informed Electorate." American Political Science Review 105 (August): 496-515.
Chong, Dennis, and James N. Druckman. 2007. "Framing Public Opinion in Competitive Democracies." American Political Science Review 101 (November): 637-55.

Chong, Dennis, and James N. Druckman. 2010. "Dynamic Public Opinion." American Political Science Review 104 (November): 663-80.

Chong, Dennis, and James N. Druckman. 2011. "Identifying Frames in Political News." In Sourcebook for Political Communication Research, eds. Erik P. Bucy and R. Lance Holbert. New York: Routledge, 238-67.

Chong, Dennis, and James N. Druckman. N.d. "Strategies of Counterframing." Journal of Politics. Forthcoming.

Dancey, Logan and Paul Goren. 2010. "Party Identification, Issue Attitudes, and the Dynamics of Political Debate." American Journal of Political Science 54 (July): 686-99.

Druckman, James N. 2004. "Political Preference Formation." American Political Science Review 98 (November): 671-86.

Druckman, James N. 2010. "Competing Frames in a Political Campaign." In Winning with Words, eds. Brian F. Schaffner and Patrick J. Sellers. New York: Routledge, 101-20.

Druckman, James N. 2011. "What's It All About?: Framing in Political Science." In Perspectives on Framing, ed. Gideon Keren. New York: Psychology Press/Taylor and Francis, 279-302.

Druckman, James N. 2012. "The Politics of Motivation." Critical Review: A Journal of Politics andSociety 24 (2): 199-216. 
Druckman, James N., and Toby Bolsen. 2011. "Framing, Motivated Reasoning, and Opinions about Emergent Technologies." Journal of Communication 61 (August): 659-88.

Druckman, James N., Jordan Fein, and Thomas J. Leeper. 2012. "A Source of Bias in Public Opinion Stability." American Political Science Review 106 (May): 430-54.

Druckman, James N., Cari Lynn Hennessy, Kristi St. Charles, and Jonathan Weber. 2010. "Competing Rhetoric over Time." Journal of Politics 72 (January): 136-48.

Druckman, James N., and Thomas J. Leeper. 2012a. "Learning More from Political Communication Experiments: Pretreatment and Its Effects." American Journal of Political Science 56 (October): 87596.

Druckman, James N., and Thomas J. Leeper. 2012b. "Is Public Opinion Stable?" Daedalus 106: 430-54.

Druckman, James N., and Kjersten R. Nelson. 2003. "Framing and Deliberation." American Journal of Political Science 47 (October): $729-45$.

Fiorina, Morris P., and Samuel J. Abrams. 2008. "Political Polarization in the American Public." Annual Review of Political Science 11 (June): 563-88.

Goren, Paul, Christopher M. Federico, and Miki Caul Kittilson. 2009. "Source Cues, Partisan Identities, and Political Value Expression." American Journal of Political Science 55 (October): 805-20.

Green, Donald P., Bradley Palmquist, and Eric Schickler. 2002. Partisan Hearts and Minds. New Haven, CT: Yale University Press.

Hänggli, Regula, and Hanspeter Kriesi. 2010. "Political Framing Strategies and Their Impact on Media Framing in a Swiss DirectDemocratic Campaign." Political Communication 27 (2): 141-57.

Hetherington, Marc. 2009. "Putting Polarization in Perspective." British Journal of Political Science 39 (April): 413-48.

Iyengar, Shanto, Gurav Sood, and Yphtach Lelkes. 2012. "Affect, Not Ideology: A Social Identity Perspective on Polarization." Public Opinion Quarterly 76 (3): 405-31.

Jacobson, Gary C. 2008. A Divider, Not a Uniter. New York: Pearson.

Jerit, Jennifer. 2009. "How Predictive Appeals Affect Policy Opinions." American Journal of Political Science 53 (April): 411-26.

Johnson, Dominic D. P., and James H. Fowler. 2011. "The Evolution of Overconfidence." Nature 447 (September): 317-20.

Krauss, Clifford, and John M. Broder. 2012. "Oil Drilling in the Gulf Rebounds as Prices Promote Exploration.” New York Times, March 5.

Kunda, Ziva. 1990. "The Case for Motivated Reasoning." Psychological Bulletin 108 (November): 480-98.

Lascher, Edward L., and John L. Korey. 2011. "The Myth of the Independent Voter, California Style." California Journal of Politics and Policy 3 (January).

Lavine, Howard, Christopher Johnston, and Marco Steenbergen. 2012. The Ambivalent Partisan. Oxford: Oxford University Press.

Levendusky, Matthew S. 2010. "Clearer Cues, More Consistent Voters." Political Behavior 32 (1): 111-31.

Lupia, Arthur. 1994. "Shortcuts versus Encyclopedias: Information and Voting Behavior in California Insurance Reform Elections." American Political Science Review 88 (March): 63-76.

Mackie, Diane M., Leila T. Worth, and Arlene G. Asuncion. 1990. "Processing of Persuasive In-group Messages." Journal of Personality and Social Psychology 58 (May): 812-22.

Mansbridge, Jane. 1983. Beyond Adversary Democracy. Chicago: University of Chicago Press.

McCarty, Nolan, Howard Rosenthal, and Keith T. Poole. 2006. Polarized America. Cambridge, MA: MIT Press.

Nelson, Thomas E., Rosalee A. Clawson, and Zoe M. Oxley. 1997. "Media Framing of a Civil Liberties Conflict and Its Effect on Tolerance." American Political Science Review 91 (3): 567-83.

Nicholson, Stephen P. 2011. "Dominating Cues and the Limits of Elite Influence." Journal of Politics 73 (October): 1165-77.

Nicholson, Stephen P. 2012. "Polarizing Cues." American Journal of Political Science 56 (January): 52-66.

Nicholson, Stephen P., and Evan Heit. 2012. "The Partisan Founda- tions of Citizen Competence." University of California, Merced. Typescript.

Nir, Lilach. 2011. "Motivated Reasoning and Public Opinion Perception." Public Opinion Quarterly 75 (3): 504-32.

O'Keefe, Daniel J. 2002. Persuasion. Thousand Oaks, CA: Sage.

Payne, John W., James R. Bettman, and Eric J. Johnson. 1993. The Adaptive Decision Maker. New York: Cambridge University Press.

Petersen, Michael Bang, Martin Skov, Søren Serritzlew, and Thomas Rams $\varnothing$ y. N.d. "Motivated Reasoning and Political Parties: Evidence for Increased Processing in the Face of Party Cues." Political Behavior. Forthcoming

Petersen, Michael Bang, Rune Slothuus, and Lise Togeby. 2010. "Political Parties and Value Consistency in Public Opinion Formation." Public Opinion Quarterly 74 (3): 530-50.

Peterson, Erik. 2011. "Competitive Partisan Issue Framing." Undergraduate honors thesis. Northwestern University.

Pew Research Center for the People and the Press Political Survey. 2011. iPOLL Databank, Roper Center for Public Opinion Research, University of Connecticut (April 22, 2011).

Pew Research Center/National Journal Congressional Connection Poll. 2010. iPOLL Databank, Roper Center for Public Opinion Research, University of Connecticut (April 22, 2011).

Prior, Markus. 2007. "Is Partisan Bias in Perceptions of Objective Conditions Real?" Presented at the Annual Meeting of the Midwest Political Science Association, Chicago.

Redlawsk, David. 2002. "Hot Cognition or Cool Consideration." Journal of Politics 64 (November): 1021-44.

Schattschneider, E. E. 1960. The Semisovereign People. Hindsdale, IL: Holt, Rinehart and Winston.

Slothuus, Rune. 2010. "When Can Political Parties Lead Public Opinion?" Political Communication 27 (May): 158-77.

Slothuus, Rune. 2011. "Assessing the Influence of Political Parties on Public Opinion." Presented at the Annual Meeting of the International Society of Political Psychology, Istanbul, Turkey.

Slothuus, Rune, and Claes H. de Vreese. 2010. "Political Parties, Motivated Reasoning, and Issue Framing Effects." Journal of Politics 72 (3): 630-45.

Smith, Eric R. A. N. 2002. Energy, the Environment, and Public Opinion. Boulder, CO: Rowman \& Littlefield.

Smith, Joanne R., Deborah J. Terry, Timothy R. Crosier, and Julie M. Duck. 2005. "The Importance of the Relevance of the Issue to the Group in Voting Intentions." Basic and Applied Social Psychology 27 (2): 163-70.

Sniderman, Paul M., Richard A. Brody, and Philip E. Tetlock. 1991. Reasoning and Choice: Explorations in Political Psychology. Cambridge: Cambridge University Press.

Sniderman, Paul M., and Edward H. Stiglitz. 2012. The Reputational Premium. Princeton, NJ: Princeton University Press.

Sniderman, Paul, and Sean M. Theriault. 2004. "The Structure of Political Argument and the Logic of Issue Framing." In Studies in Public Opinion: Attitudes, Nonattitudes, Measurement Error, and Change, eds. W. E. Saris and P. M. Sniderman. Princeton, NJ: Princeton University Press, 133-65.

Taber, Charles S., and Milton Lodge. 2006. "Motivated Skepticism in the Evaluation of Political Beliefs." American Journal of Political Science 50 (July): 755-69.

Transue, John E., Daniel J. Lee, and John H. Aldrich. 2009. "Treatment Spillover Effects across Survey Experiments." Political Analysis 17 (2): 143-61.

Ura, Joseph Daniel, and Christopher R. Ellis. 2012. "Partisan Moods." Journal of Politics 74 (January): 277-91.

Visser, Penny S., George Y. Bizer, and Jon A. Krosnick. 2006. "Exploring the Latent Structure of Strength-Related Attitude Attributes." In Advances in Experimental Social Psychology 38. Ed. M. Zanna. San Diego: Academic Press.

White, Jonathan, and Lea Ypi. 2011. "On Partisan Political Justification.” American Political Science Review 105 (May): 381-96.

Wyer, Natalie A. 2010. "Selective Self-Categorization." Journal of Social Psychology 150 (September): 452-70. 